\title{
Dinámica de la pobreza urbana en el Perú y en Madagascar 1997-1999: un análisis sobre datos de panel
}

Dynamique de la pauvreté urbaine au Pérou et à Madagascar 1997-1999: une analyse sur données de panel

Urban Poverty Dynamics in Peru and Madagascar 1997-1999: A Panel Data

Analysis

Javier Herrera y François Roubaud

\section{OpenEdition}

Journals

Edición electrónica

URL: http://journals.openedition.org/bifea/6688

DOI: $10.4000 /$ bifea.6688

ISSN: 2076-5827

Editor

Institut Français d'Études Andines

Edición impresa

Fecha de publicación: 1 diciembre 2002

Paginación: 495-552

ISSN: 0303-7495

Referencia electrónica

Javier Herrera y François Roubaud, « Dinámica de la pobreza urbana en el Perú y en Madagascar

1997-1999: un análisis sobre datos de panel », Bulletin de l'Institut français d'études andines [En línea],

31 (3) | 2002, Publicado el 08 diciembre 2002, consultado el 09 diciembre 2020. URL : http://

journals.openedition.org/bifea/6688; DOI : https://doi.org/10.4000/bifea.6688

\section{(c) (†) $\odot$}

Les contenus du Bulletin de l'Institut français d'études andines sont mis à disposition selon les termes de la licence Creative Commons Attribution - Pas d'Utilisation Commerciale - Pas de Modification 4.0 International. 


\title{
DINÁMICA DE LA POBREZA URBANA EN EL PERÚ Y EN MADAGASCAR 1997-1999: UN ANÁLISIS SOBRE DATOS DE PANEL
}

\author{
Javier HERRERA*, François ROUBAUD ${ }^{* *}$
}

\section{Resumen}

La prioridad otorgada a la lucha contra la pobreza por los países en desarrollo y los organismos internacionales llevó a refinar el diagnóstico de las diferentes formas de pobreza, así como de las políticas que se les deben aplicar. En particular, la distinción entre pobreza crónica y pobreza transitoria indujo un cuestionamiento sobre las políticas del pasado, consideradas como muy asistencialistas, y su nueva orientación hacia políticas favoreciendo salidas de pobreza y protegiendo a los grupos vulnerables. El modelo subyacente a esta nueva conceptualización postula que la pobreza crónica proviene de un déficit estructural de dotación, mientras que la pobreza transitoria resulta de choques adversos que se deberían prevenir. Este enfoque implica la ampliación de la visión estática tradicional del análisis centrado en la dinámica individual de la pobreza. Sin embargo, a la fecha, existen pocos estudios empíricos sobre este tema en los países en desarrollo, esencialmente por razones de falta de datos de panel, que son requeridos para este tipo de análisis. Además, extraer conclusiones generales de esos trabajos resulta difícil debido a la gran heterogeneidad de las muestras, de los datos y de las metodologías, lo que restringe el campo de comparación entre países. Nuestro estudio acerca de la dinámica de la pobreza urbana en Madagascar y Perú constituye un aporte inicial en esta dirección. Al adoptar métodos rigurosamente comparables e incluir un amplio espectro de situaciones para estos países, cuyos niveles de desarrollo y coyuntura económica son muy contrastados, buscamos identificar los rasgos generales y específicos de la pobreza crónica y transitoria.

La primera parte presenta el contexto macroeconómico de los tres años estudiados (19971999), ubicándolos en una perspectiva histórica, así como las principales características de los datos utilizados y las metodologías empleadas. Un balance de la evolución de la pobreza y de las desigualdades por medio de un análisis de sección transversal es el objeto de la segunda parte. La estimación de los intervalos de confianza y el análisis en términos de dominación estocástica permiten asentar la robustez de los resultados basados en la comparación con los índices FGT tradicionales. También se lleva a cabo una descomposición crecimiento/

\footnotetext{
* Investigador del IRD-INEI, UR 047, CIPRE. E-Mail:jherrera@inei.gob.pe

*** Investigador del IRD-DIAL, responsable del UR 047, CIPRE. E-mail: roubaud@ dial.prd.fr
} 
desigualdades de la evolución de la pobreza. La tercera parte es dedicada al análisis descriptivo de las transiciones de pobreza, las que se encuentran modeladas en la cuarta parte. Finalmente, la conclusión resume los principales resultados del estudio y explora algunas implicancias para las políticas de lucha contra la pobreza.

Palabras claves: Dinámica de la pobreza, desigualdad, Perú, Madagascar, modelo logitmultinomial, panel.

\title{
DYNAMIQUE DE LA PAUVRETÉ URBAINE AU PÉROU ET À MADAGASCAR 1997-1999 : UNE ANALYSE SUR DONNÉES DE PANEL
}

\section{Résumé}

La priorité accordée par les pays en développement et par les organismes internationaux à la lutte contre la pauvreté a conduit à affiner le diagnostic sur les différentes formes de pauvreté et les politiques qu'il convient de leur appliquer. En particulier, la distinction entre pauvreté chronique et pauvreté transitoire a induit une remise en cause des politiques jugées trop assistentialistes du passé, et à les réorienter vers des politiques favorisant les sorties de pauvreté et protégeant les groupes vulnérables. Le modèle sous-jacent à cette nouvelle conceptualisation postule que la pauvreté chronique provient d'un déficit structurel de dotation tandis que la pauvreté transitoire résulte de chocs adverses qu'il convient de prévenir. Une telle approche suppose élargir la vision statique traditionnelle à une analyse centrée sur la dynamique individuelle de la pauvreté. Or à ce jour, on compte peu d'études empiriques dans ce domaine dans les PED, essentiellement pour des raisons d'absence de données de panel, qui sont requises pour ce type d'analyses. De plus, il est difficile de tirer des conclusions générales de ces travaux, du fait de la grande hétérogénéité des échantillons, des données et des choix méthodologiques, qui restreignent le champ des comparaisons possibles entre pays. Notre étude sur la dynamique de la pauvreté urbaine à Madagascar et au Pérou est une première contribution dans cette direction. En adoptant des méthodes rigoureusement comparables, et en couvrant un large spectre de situations avec ces deux pays, dont la conjoncture économique et les niveaux de développement sont très contrastés, nous cherchons à identifier les traits généraux et spécifiques de la pauvreté chronique et transitoire.

La première section présente le contexte macro-économique des trois années sous revue (1997-1999) en les replaçant dans une perspective historique, ainsi que les principales caractéristiques des données utilisées et les choix méthodologiques retenus. Un bilan des évolutions de la pauvreté et des inégalités à travers l'analyse en coupe transversale fait l'objet de la deuxième section. L'estimation des intervalles de confiance et l'analyse en termes de dominance stochastique permettent d'asseoir la robustesse des résultats fondés sur la comparaison des indices FGT traditionnels. Une décomposition croissance/inégalité de l'évolution de la pauvreté est aussi menée. La troisième section est consacrée à l'analyse descriptive des transitions de pauvreté, qui seront modélisées dans la quatrième section. Enfin la conclusion résume les principaux résultats de l'étude et explore quelques implications qui peuvent en être dérivées pour les politiques de lutte contre la pauvreté.

Mots clés : Dynamique de la pauvreté, inégalité, Pérou, Madagascar, modèle logit multinomial, panel.

\section{URBAN POVERTY DYNAMICS IN PERU AND MADAGASCAR 1997-1999: A PANEL DATA ANALYSIS}

\begin{abstract}
The limits of the welfare-type (asistencialista) anti-poverty policies promoted in the eighties in order to counter the effects of structural adjustments (SDA) have led to an awareness
\end{abstract}


of the need to reflect on interactions among anti-poverty programs and, more importantly, to conceive and put in place anti-poverty policies adapted to the different existing types of poverty, as well as to draw attention to the factors associated to exits from poverty.

However, the small number of studies on poverty dynamics in developing countries and methodological differences among them have made it difficult to identify what the implications are for anti-poverty policies. Are the factors associated to chronic poverty and vulnerability the same from one country to the next? What are the features that characterize exits from poverty?

Based on a large sample of Peruvian and Madagascan urban households (1997-1999), the importance of poverty transitions was examined, as well as the characteristics of the temporarily and the chronically poor, with respect to those of non-poor households. Then, through a multinomial logit model, the specific contribution of household characteristics (demographics, human and physical capital), but also of shocks -related to both demographics and job marketexperienced by these households, on chronic poverty and poverty entries and exits was highlighted. In this analysis, the impact of "geographic" variables linked to neighborhoods (provision of public goods, income levels, human capital and employment structure, among others) on poverty transitions was also considered. The two latter groups of variables are rarely considered in empirical research on developing countries (shocks are set aside in analyses because of the simultaneity biases that exist when no more than two years of observation are available). Result comparability was ensured by defining the variables and formulating the econometric model in a rigorously identical manner in both countries.

The factors associated to permanent poverty amply cover the characteristics generally identified in analyses on "static" poverty correlates. Nevertheless, these results do not confirm the idea that only shocks are relevant to temporary forms of poverty. The type and quality of entry on the job market, as well as the features of the residence neighborhood, turn out to be equally relevant in the analysis of poverty dynamics. These results suggest that the spatial "inequality" dimension should be added to analyses on income and poverty transition dynamics.

Key words: Poverty dynamics, inequality, Peru, Madagascar, multinomial logit, panel.

\section{INTRODUCCIÓN}

Desde hace algunos años la lucha contra la pobreza se ha convertido en objetivo central de las políticas de desarrollo. El balance mitigado de dos decenios de estabilización y ajuste estructural sobre el nivel de vida de los hogares en los países en desarrollo ha llevado a la comunidad financiera internacional, conducida por las instituciones de Breton Woods, a reconsiderar su estrategia y a dotarse de nuevos instrumentos para llevar a buen término lo que parece ser una verdadera cruzada. Los "documentos marco de política económica" (DCPE), que condicionaban el acceso a la ayuda financiera de las agencias internacionales de ayuda se titulan en adelante "documentos estratégicos de reducción de la pobreza" (DSRP). El tradicional "crédito de ajuste estructural" (CAS) del Banco Mundial ha sido reemplazado por el "crédito de apoyo para la reducción de la pobreza" (CSRP). Incluso el FMI, hasta entonces poco involucrado en esta lucha, ha ajustado el paso transformando su "facilidad de ajuste estructural reforzado" (FASR) en "facilidad para la reducción de la pobreza y para el crecimiento" (FRPC). Un nuevo dispositivo de reducción de la deuda acaba de completar los acuerdos de anulación y de reescalonamiento anteriores (Club de París, 
términos de Toronto, Nápoles, Lyon, etc.). Para marcar su compromiso los principales donadores han señalado ocho objetivos de desarrollo del milenio (OID), a través de la iniciativa en favor de los países pobres muy endeudados (PPTE), de los cuales el primero consiste en dividir por dos la incidencia de la extrema pobreza entre 1990 y 2015. Si bien la prioridad en la lucha contra la pobreza se focaliza antes que nada en los países menos avanzados, alcanza igualmente a los países de ingreso intermedio, para abarcar así al conjunto de los países en desarrollo (PED) y en transición.

Esta nueva orientación de las políticas de desarrollo plantea un verdadero desafío a la comunidad científica, y en particular a los economistas, y cuya gran amplitud es mostrada por el informe sobre el desarrollo en el mundo del Banco Mundial (2000) titulado "Combatir la pobreza". El objetivo del presente estudio es contribuir a esa vasta reflexión a través del análisis comparado de la dinámica individual de la pobreza en dos países en desarrollo, Madagascar y el Perú, a fines de los años 90. El interés de este trabajo descansa sobre la rigurosa confrontación de los determinantes de las transiciones de pobreza a partir de dos paneles de hogares urbanos, a lo largo de un período de tres años, en contextos muy contrastados: el primero de uno de los países más pobres del mundo en fase de recuperación rápida, y el otro en un país emergente inmerso en una coyuntura recesiva.

Los juicios sobre los decepcionantes progresos obtenidos en materia de niveles de vida y de desigualdad a nivel internacional reposan generalmente sobre una visión estática, fundada sobre la comparación de indicadores de un año dado con los de los años precedentes. Solamente se consideran los saldos netos de pobreza, y se dejan de lado las trayectorias de los hogares a lo largo del tiempo. Las conclusiones obtenidas mediante aproximaciones estáticas en cuanto a la persistencia o no de la pobreza suponen implícitamente que los pobres constituyen una categoría fija de hogares con características específicas y de carácter permanente. Ello supone, pues, que no hay (o hay poca) redistribución de los ingresos que beneficien a los segmentos más bajos de la distribución de los ingresos.

El seguimiento de un panel de hogares permite abordar importantes cuestiones hasta entonces sin respuesta en los PED. ¿Qué proporción de la población se encuentra en situación de pobreza permanente? ¿Qué porcentaje de pobres de un año dado corresponde a pobres transitorios? ¿Cuál es la importancia de la movilidad económica de los hogares y, en particular, la que se da entre pobres y no pobres? ¿Poseen los pobres permanentes características diferentes de las de los transitorios? ¿Son los factores determinantes del ingreso a la condición de pobres los mismos que los de las salidas de la pobreza? ¿Qué cambios en las características de los hogares y de su entorno están asociados con la movilidad ascendiente y descendiente? ¿De qué manera esta aproximación dinámica a la pobreza conduce a reconsiderar las políticas de lucha contra la pobreza y a apreciar su eficacia? Pocos países en desarrollo están en posición de responder a estas preguntas, pues ello supone disponer de un seguimiento a gran escala de los mismos hogares a lo largo del tiempo; ahora bien, las encuestas que lo permiten son extremadamente raras en estos países.

El examen de las características y de los determinantes de las transiciones entre pobreza y no pobreza debería permitir aprehender de manera más fina las diferentes 
formas de pobreza, distinguiendo sobre todo pobres crónicos de pobres transitorios, y por consiguiente la aplicación de políticas diferenciadas, vinculadas con los factores de riesgo específicos de cada una de estas categorías; todo ello al margen de los problemas de focalización ("filtración" y "exclusión”) ocasionados por un fuerte grado de movilidad entre pobreza y no pobreza.

Si bien existe una abundante literatura en los países desarrollados sobre el tema de la movilidad económica y las dinámicas de pobrezas basada en paneles de hogares (ver por ejemplo Jenkins, 1998), tales estudios siguen siendo aún muy raros en los PED. La falta de datos longitudinales es la causa principal de ello. Según Yaqub (2000a) solamente 5 de 44 países de bajo desarrollo humano, y 7 de los 66 países de desarrollo humano intermedio, siguiendo la clasificación del PNUD, disponían de datos longitudinales. En una obra reciente consagrada a este problema, Baulch \& Hoddinot (2000) confirmaban esta laguna. Su obra, que reúne seis estudios originales (Etiopía, África del Sur, China, Pakistán, Simbabwe y Chile), constituye la primera tentativa de extraer enseñanzas de este tipo de enfoque. Sin embargo, la extremada diversidad de los paneles utilizados (en términos de cobertura geográfica, de período de referencia, de tipo de muestreo, de indicadores de bienestar, de línea de pobreza, etc.) limita considerablemente el alcance analítico de los diferentes estudios de casos, sobre todo en su dimensión comparativa.

Al inscribirse en esta misma veta temática, nuestro artículo constituye, hasta donde conocemos, la primera tentativa de análisis comparativo de la dinámica de la pobreza, al descansar sobre una aproximación y opciones metodológicas comunes. Al movilizar dos paneles de gran calidad, y al adoptar procedimientos homogéneos de construcción de las variables de análisis, nos situamos en las mejores condiciones para estudiar los factores de riesgo para la entrada en la pobreza o los asociados con la pobreza crónica. Se trata, pues, de saber si el nivel de desarrollo y la coyuntura económica actúan sobre el grado de "fluidez" de la pobreza. Además, el hecho de disponer de tres años consecutivos permite incluir entre las variables explicativas de las transiciones de pobreza los shocks sufridos por los hogares (demográficos y económicos), evitando así los problemas de endogeneidad, que no pueden ser solucionados cuando sólo se dispone de dos puntos en el tiempo. En fin, hemos tratado de ampliar el campo de los factores explicativos de las transiciones de pobreza añadiendo a las tradicionales características individuales de los hogares las variables vinculadas con el barrio de residencia, a fin de apreciar eventuales efectos de localización geográfica sobre la pobreza.

La primera sección presenta el contexto macroeconómico de los tres años en estudio (1997-1999), resituándolos en una perspectiva histórica, así como las principales características de los datos utilizados y las opciones metodológicas elegidas. El tema de la segunda sección es un balance de las evoluciones de la pobreza y de las desigualdades por medio del análisis en corte transversal. La estimación de los intervalos de confianza y el análisis en términos de dominancia estocástica permiten comprobar la solidez de los resultados fundados sobre la comparación de los índices FGT tradicionales. También efectuamos una decomposición de crecimiento/desigualdad de la evolución de la pobreza. La tercera sección está consagrada al análisis descriptivo 
de las transiciones de pobreza, las mismas que serán modelizadas en la cuarta sección. En fin la conclusión resume los principales resultados del estudio y explora algunas implicaciones que pueden derivarse de ellos para la política de lucha contra la pobreza.

\section{PERSPECTIVA GENERAL}

\section{1. El contexto macroeconómico en los años 90}

A pesar de tener niveles de desarrollo muy diferentes, al ser el PBI per cápita del Perú diez veces superior al de Madagascar (2400 y 250 dólares, respectivamente), ambos países han seguido políticas muy semejantes a lo largo de los años 90. Como consecuencia de los fracasos de las estrategias de políticas económicas del pasado, a ejemplo de numerosos PED, han tratado de reorientar su modelo de crecimiento apostando a la liberalización y a la apertura a la economía mundial. El cambio de rumbo fue adoptado a mediados de los años 80 en Madagascar, mientras que el Perú ha esperado 1990, con la llegada al poder del presidente Fujimori.

\section{2. El Perú}

Los años 1990 fueron de profundas reformas institucionales y de shoks macroeconómicos que marcan una ruptura con el régimen clientelista anterior, cuya "heterodoxia" económica había hundido al país en el caos (hiperinflación, etc.). Las empresas públicas y para-públicas fueron en su gran mayoría privatizadas, se suprimieron las subvenciones y controles de precios, mientras que el gobierno procedía a una reforma sin precedentes del mercado de trabajo. Se abolió prácticamente la estabilidad laboral, y se disminuyeron fuertemente los costos del despido. Con el incentivo de compensaciones financieras más de 150000 funcionarios dejaron sus empleos, mientras que paralelamente, la desregulación del mercado arrastró consigo la multiplicación del trabajo precario. Así en la capital, la proporción de trabajadores estables pasó de 65\% en 1989 a $42 \%$ en 1994, luego a 23\% en 1997 (Vedera, 2000). Al mismo tiempo la tasa de sindicalización se desplomó, pasando de 58\% en 1989 hasta no llegar al 13\% en 1997.

Después de una primera fase de recesión brutal consecutiva al "fujishock" (el PBI disminuye 5\% en 1990), el Perú conoce un período de fuerte expansión entre 1993 y 1997 (1). El PBI per cápita crece en más de 6\% por año. Sin embargo a semejanza de los demás países latinoamericanos el crecimiento de la economía peruana se hizo brutalmente más lento, para después hacerse negativo como resultado de la crisis asiática a partir del segundo semestre de 1997. Al cese del flujo de ingreso de capitales a corto plazo, y a la caída de los precios de los principales productos de exportación, se añaden los efectos devastadores del fenómeno del El Niño. Apreciado desde una perspectiva de largo plazo, este salto de más de 50\% del PBI, bajo el régimen de Fujimori, finalmente no habría permitido alcanzar sino el nivel logrado en 1972.

(1) Es interesante notar que los últimos años del gobierno de Alan García han sido de otro modo más nefastos para el crecimiento que el "fujishoc": entre 1987 y 1989 el PBI per cápita baja 22\%, contra menos de $7 \%$ entre 1989 y 1990 ( $c f$. Gráfico 1). 
En 1998 y 1999 el país registra una disminución del PBI per cápita de -2,1\%, y $-0,3 \%$. El dualismo de la economía peruana, en la que el crecimiento es impulsado por un sector de exportación de materias primas dinámico, esconde la amplitud de la crisis para los hogares, que son las que padecen en primer lugar los efectos de la contracción del mercado interno. El consumo privado per cápita disminuye de -2,7\% y de -1,9\% en 1998 y 1999, después de haber crecido en $2,4 \%$ bajo el impulso de un relanzamiento de los gastos públicos en el año precedente, los cuales habían aumentado en 7,6\%, en ese año. La dimensión del retroceso del consumo registrado por las cuentas nacionales se ve coroborado por los resultados de las investigaciones ENAHO en los hogares. Los gastos reales per cápita caen en ellos en -8\% entre 1997 y 1999.

Esta degradación de la actividad económica se traduce en una agravación de las tasas de desocupación (de 7,2\% a 9\% entre 1996 y 1999), sin embargo, poco sensible a los shoks macroeconómicos (por causa sobre todo de la falta de un seguro contra el desempleo y de una fuerte proporción de informales independientes). Las remuneraciones de los obreros en las empresas con más de 10 trabajadores disminuyen en $-0,5 \%$ entre 1997 y 1998 , y en 1,3\% el año siguiente. El descenso de los niveles de vida puede leerse indirectamente en las estrategias de los hogares para enfrentar la crisis. Así, la tasa de actividad en la capital pasa de 59,7\% en 1996 a 64\% en 1999.

En este desfavorable contexto, la incidencia de la pobreza a nivel nacional aumenta de manera significativa entre 1998 y 1999 (pasa de 42,4\% a 47,5\%) (2). La pobreza se ha hecho más urbana en la medida en que el aumento de pobres en tres cuartas partes se ha concentrado en las zonas urbanas. De este modo la tasa de pobreza aumenta de 7 puntos en la capital y en la costa urbana, mientras que, en el campo, se incrementa en casi 6 puntos. Del millón y medio de pobres adicionales entre 1997 y 1999, un 43\% procede de la capital y 30\% de las ciudades costeñas. En contraste con esta situación, la incidencia de la extrema pobreza se mantiene estable entre 1997 y 1999 (18,2\% y 18,4\% respectivement)gracias principalmente a una disminución de 0,6 puntos de la incidencia en el área urbana, mientras que se incrementa en casi 3 puntos en la zona rural. Esta contrastada evolución de la pobreza no se halla ciertamente desvinculada de las políticas de reformas adoptadas. Estas son de tal naturaleza que afectan más al sector moderno y urbano de la economía. Paralelamente, el gobierno ponía en marcha un programa de lucha contra la pobreza y procedía a un aumento sin precedentes en los gastos sociales, que se duplicaron entre 1993 y 1998, pasando de \$63 a \$174 per cápita, y han sido en gran parte destinados a las ciudades del interior del país.

(2) Los niveles de pobreza citados en esta ocasión, tanto en el caso del Perú como de Madagascar, corresponden a las cifras oficiales. Ellos no son comparables a las cifras presentada en el resto del presente estudio debido a diferencias en los datos usados y opciones metodológicas (cobertura geográfica, línea de pobreza, indicador de bienestar, etc.). 
Cuadro 1 - Madagascar y el Perú en cifras (1999).

\begin{tabular}{|c|c|c|c|c|c|}
\hline & Madag. & Perú & & Madag. & Perú \\
\hline $\begin{array}{l}\text { Superficie }(1000 \\
\left.\mathrm{km}^{2}\right)\end{array}$ & 587 & 1285 & $\begin{array}{l}\text { PBI (miles de millones } \\
\text { de us\$) }\end{array}$ & 3,7 & 51,9 \\
\hline Población (millones) & 14,6 & 25,2 & PBI/per cápita (us\$) & 250 & 2130 \\
\hline $\begin{array}{l}\text { Tasa de crecimiento } \\
\text { población } \%\end{array}$ & 2,8 & 1,7 & $\begin{array}{l}\text { Tasa de inversión } \\
\text { (\% PBI) }\end{array}$ & 12 & 22 \\
\hline Población urbana $(\%)$ & 29 & 72 & Presión fiscal (\%PBI) & 11 & 12 \\
\hline $\begin{array}{l}\text { Esperanza de vida } \\
\text { (en años) }\end{array}$ & 58 & 69 & Deuda externa $(\% \mathrm{PBI})$ & 123 & 61 \\
\hline
\end{tabular}

\subsection{Madagascar}

Madagascar se ha embarcado desde hace cerca de 15 años en un proceso de ajuste de su economía. Si en una primera fase se puso el acento en la estabilización financiera, pronto se hicieron visibles los límites de tal política. La segunda fase se ha propuesto instaurar un cambio en profundidad del modo de regulación económica. Así, y a pesar de las vacilaciones, las autoridades han iniciado una amplia serie de reformas destinadas a promover la economía de mercado. Entre las medidas que se han tomado, se puede citar:

- la supresión de los impuestos a la exportación;

- una fuerte disminución de los derechos e impuestos de importación;

- la liberalización de los circuitos de comercialización, así como de los precios que hasta entonces eran administrados;

- la instauración de un regimen de empresas exportadoras francas;

- la implantación de un sistema de cambios flotante;

- el retiro del Estado de las actividades productivas, sobre todo en el sector bancario.

Si bien en ciertos ámbitos persisten las dificultades en la continuación de las reformas sectoriales (privatización de empresas públicas, reforma de la función pública, etc.), las etapas que se han franqueado reflejan un avanzado grado de compromiso con el proceso de instauración de una economía de mercado y apertura al exterior. De hecho, a partir de inicios de los años 90, Madagascar ha llevado a cabo una doble transición: económica, desde luego, pero también política. El país ha enterrado con éxito una experiencia de tipo socialista que ha durado dos decenios, en favor de un régimen democrático (elecciones libres, libertad de prensa, emergencia de la sociedad civil, etc.). Fortificado por estos avances, Madagascar reanudó en 1996 sus lazos con la comunidad financiera internacional, lo que le ha permitido beneficiarse con numerosos créditos y remisión de deudas (CAS, FASR, Club de París, etc.). 
No obstante, a pesar de la amplitud del programa de reformas, la economía malgache se estancó en la primera mitad de los años 90. La inestabilidad política crónica que reinó durante este período es ampliamente responsable de esta fase de ajuste sin crecimiento. Finalmente no fue sino a partir de 1997 que se hizo sentir la recuperación: por primera vez después de muchos años, el PBI per cápita mejora ligeramente $(+1 \%)$. Desde entonces, el proceso se acelera, y el crecimiento ronda los 5\% en el año 2000. Esta mejoría es por completo excepcional en la historia económica de Madagascar. Hay que remontarse hasta fines de los años 60 para encontrar una situación tan favorable como esta. La inflación se halla bajo control, después del desliz de los años 1994/ 1996, engendrado por la liberación de la tasa de cambio. Si en conjunto la inserción de Madagascar en la economía mundial no ha mejorado sustancialmente, por efecto de la inercia de las exportaciones tradicionales de productos primarios y del estancamiento del flujo de capitales privados externos, algunos sectores han sabido beneficiarse. Es el caso del turismo, de la pesca, pero sobre todo de la zona franca industrial de exportación, cuyo excepcional dinamismo contrasta con el marasmo que caracteriza a sus homólogos del África subsahariana (con excepción de la isla Mauricio).

La evolución macroeconómica que muestran los datos de la contabilidad nacional no refleja bien la dinámica del ingreso de los hogares, sobre todo por el hecho de su baja calidad. Las encuestas realizadas en los hogares permiten poner en evidencia un boom sin precedentes de la economía urbana, mientras que al mismo tiempo las zonas rurales se estancan. En la ciudad, los empleos informales, que progresivamente habían colonizado el mercado de trabajo retroceden, en tanto que la remuneración real del trabajo y el ingreso per cápita de los hogares registran un aumento de $43 \%$ y $35 \%$, respectivamente, entre 1995 y 1999 (Razafindrakoto \& Roubaud, 1999). Esta excepcional mejoría, que beneficia a todas las categorías de hogares, se ve estimulada por una política de salarios públicos y privados muy generosa. En cambio las áreas rurales, masivamente al margen del mercado, no se benefician con el retorno del crecimiento. Este dualismo engendra un aumento de las desigualdades entre las zonas urbanas y rurales donde los bolsones de pobreza se hallan masivamente concentradas (84\% de los pobres).

La evolución de la pobreza sigue las fluctuaciones de los ingresos de los hogares. Según los resultados de las encuestas EPM realizadas en 1993, 1997 y 1999, la incidencia de pobreza ha retrocedido ligeramente entre 1997 y 1999 al nivel nacional (-2 puntos). Sin embargo, esta constatación global oculta dinámicas divergentes entre los medios urbano y rural. Mientras que la pobreza rural se mantiene a niveles elevados $(76 \%$ y $76,7 \%)$, baja en más de 11 puntos en las ciudades $(63,2 \%$ y 52,1\%). En ambos casos la incidencia de la pobreza es siempre superior a la registrada en 1993 (Razafindravonona et al., 2001). En una perspectiva a más largo plazo, los niveles de vida de los hogares permanecen muy por debajo del observado a comienzos de los años 70, ya que entre 1971, el año más fasto, y 1996, el punto más bajo, el consumo per cápita se había reducido a la mitad. En el caso de la capital, donde se disponen de datos desde la independencia, el nivel de vida ha bajado en 30\% entre 1961 y 1998 (Ravelosoa, 2001). El impacto de las políticas específicas de lucha contra la pobreza (transferencias, gastos sociales, etc.) sigue siendo marginal por causa de la irrisoria cuantía de los recursos presupuestales (la tasa de presión fiscal difícilmente alcanza el 10\% del PIB). 


\section{Gráfico 1 - Evolución del PBI per cápita entre 1960-2000.}



Fuentes: INSTAT, Madagascar, Banco Central de Reserva del Perú, nuestros propios cálculos.

\section{LOS DATOS Y LA MEDICIÓN DEL BIENESTAR}

Para llevar a cabo éxitosamente el análisis de las transiciones individuales de pobreza es necesario disponer de datos longitudinales. Más aún, la perspectiva comparativa que adoptamos aquí supone haber armonizado las encuestas y su procesamiento. Ambas exigencias explican por qué, a nuestro conocimiento, nunca se ha llevado a cabo un trabajo de este tipo. Enseguida presentamos brevemente los datos utilizados así como las principales opciones metodológicas adoptadas.

\section{1. La encuesta ENAHO en el Perú}

En 1996 el Instituto Nacional de Estadística e Informática (INEI) peruano, con apoyo del Banco Interamericano de Desarrollo, puso en marcha un sistema de encuestas en los hogares (ENAHO), en el marco del programa MECOVI, encuestas que permiten, entre otros, hacer un seguimiento de las condiciones de vida de la población. La constitución de un amplio panel nacional de hogares fue una de las innovaciones mayores de este programa. Además de su alcance nacional, las encuestas ofrecen la posibilidad de desagregar los resultados de acuerdo a siete dominios geográficos, además de la distinción entre zonas urbanas y rurales. El dispositivo comprende cuatro encuestas trimestrales, cada una de las cuales pone énfasis en un tema particular (violencia, empleo, salud, educación, gastos de los hogares). En el presente estudio no utilizaremos sino las encuestas realizadas el último trimestre de cada año, en la medida en que son las únicas que comportan una dimensión de panel.

Se dispone así de un panel de 1720 hogares urbanos y cerca de 8000 individuos presentes cada año en el período 1977-1999, y de dos subpaneles bianuales de 2709 y 1872 hogares en los períodos 1997-1998 y 1998-1999, respectivamente. Los hogares presentes en el panel en los tres años consecutivos representan un poco más del $40 \%$ de la muestra total en 1997 y 1998, y cerca del $78 \%$ en 1999. Además de las 
informaciones relativas a la vivienda y las características demográficas de los individuos, las encuestas tienen una sección relativa a la educación, la salud, los gastos, los ingresos, el empleo, etc.

\section{2. La encuesta-empleo MADIO en Madagascar}

A partir de 1995 el Instituto Nacional de Estadística (INSTAT), con apoyo del proyecto MADIO, ha puesto en marcha un sistema de encuestas 1-2-3 en los hogares de la aglomeración de Antananarivo (Roubaud, 2001; Rakotomanana et al., 2001). Este dispositivo se basa en una encuesta-empleo (fase 1), reiniciada cada año, sobre una muestra de 3000 hogares y más o menos 15000 individuos. Esta encuesta sirve de apoyo a las fases 2 (sector informal) y 3 (consumo, pobreza) llevadas a cabo cada tres años $(1995,1998,2001)$, según el principio de injertos de encuestas. En el año 2000 la encuesta fue ampliada a las 7 ciudades más grandes del país. Conviene subrayar que tal dispositivo es por completo excepcional en África subsahariana. En particular, por el hecho de utilizar estrictos procedimientos de control en todas las etapas (recolección de datos, depuración, tratamientos), la calidad de los datos malgaches es muy superior a la que se puede hallar en la mayorías de las encuestas de hogares en África.

Los resultados analizados aquí han sido tomados de las encuestas-empleos 19952000. En particular movilizan los datos del panel 1997-1999. En efecto, a partir de 1997 se ha adoptado el principio de renovación de un tercio de la muestra cada año (o sea 1000 hogares). Sin embargo, teniendo en cuenta las pérdidas observadas entre 1997 y 1998, la totalidad de la muestra de 1998 fue nuevamente investigada en 1999. Finalmente el panel 1997-1999 contiene una muestra explotable de 2676 hogares: 1551 entrevistados en 1997 y 1998, y 2371 en 1998 y 1999, de los cuales 1249 para los cuales disponemos de datos correspondientes a los tres años. Al ser levantadas las informaciones a nivel individual para todos los miembros del hogar, se vieron involucrados 13539 individuos pertenecientes a 2076 hogares: 8149 en 1997 y 1998 , y 12138 en 1998 y 1999, de los cuales 6478 en los tres años. La encuesta versa no sólo sobre los datos sociodemográficos tradicionales y las características de la vivienda, sino también sobre la situación de los individuos frente al mercado de trabajo (inactividad, desempleo, tipo de empleo) así como sobre los ingresos.

Cuadro 2 - Muestras utilizadas en 1997-1999.

\begin{tabular}{|l|l|l|l|l|l|l|}
\hline & \multicolumn{3}{|c|}{ Madagascar } & \multicolumn{3}{c|}{ Perú } \\
\hline Número de hogares & 1997 & 1998 & 1999 & 1997 & 1998 & 1999 \\
\hline Muestra total & 3000 & 3002 & 3002 & 4022 & 4044 & 2218 \\
Panel 1997-1998 & 1551 & 1551 & - & 2709 & 2709 & - \\
Panel 1998-1999 & - & 2371 & 2371 & - & 1872 & 1872 \\
Panel 1997-1998-1999 & 1249 & 1249 & 1249 & 1720 & 1720 & 1720 \\
\hline
\end{tabular}

Fuentes: Encuestas-empleo 1997-1999, MADIO, ENAHO 1997-1999, INEI, nuestros propios cálculos. 


\section{3. La medición del bienestar y la construcción de las líneas de pobreza}

A diferencia de numerosos estudios, los niveles de bienestar, y las mediciones de la pobreza monetaria que se derivan de ellos, se basan en el ingreso per cápita de los hogares. Si bien esta elección se basa principalmente en la necesidad de poder comparar ambos países (no disponemos de estimaciones de los gastos en el panel malgache), también se funda sobre un cierto número de consideraciones analíticas. En primer lugar, el argumento que a menudo se adelanta para privilegiar el acercamiento por la vía del gasto, y no por la del ingreso, descansa sobre la idea de que se aprehende mejor la primera en las encuestas. Este argumento no nos parece sistemáticamente justificado y sin duda resulta ampliamente sobrestimado. Nada permite asegurar que los errores de medición del consumo (valorización del autoconsumo, complejidad de los procedimiento de reconstitución del consumo a lo largo del año, recurso a la memoria de los entrevistados, etc) sean más bajos que en el caso de los ingresos (3).

Una constatación por lo demás corroborada en el caso de los países desarrollados (Verger, 2001), autor que se ve obligado a concluir lo siguiente:

"Finalmente no es más fácil medir el consumo que el ingreso: incluso es quizá más difícil, y hay que reconocer que la distribución individual del consumo, tal como ella resulta de las encuestas sobre Presupuestos de los Hogares, no tiene casi ningún valor a nivel individual, y no podría proporcionar bases para un enfoque de la desigualdad y la pobreza.."

Tal es la razón por la cual en Europa las mediciones de la pobreza se basan en el ingreso y no en los gastos.

En segundo lugar puesto que nuestro objetivo es vincular los shocks macroeconómicos y las medidas de política económica con los cambios de niveles de vida de los hogares en un corto período, la utilización de la variable correspondiente al consumo (a menudo interpretado como una medición del ingreso permanente) no parece ser la más apropiada. En cambio los ingresos aparecen más estrechamente conectados con las condiciones vigentes en el mercado de trabajo, a su vez sujeto a las influencias directas de la coyuntura macroeconómica. Además, en términos de política económica, es más fácil actuar sobre los ingresos que sobre el consumo, que no es más que una resultante de los mismos. En fin, el hecho de haber limitado nuestro campo de estudio sólo a los hogares urbanos nos permite minimizar también el papel de shoks exógenos vinculados con el clima. Así, a fines de 1997 el fenómeno de El Niño afectó duramente las actividades agrícolas en el Perú. Tanto los ingresos a la situación de pobreza (1998) como las salidas de ella (en 1999) en el medio rural están relacionados con la caída, y después con el rebote, de la producción agrícola provocada por este fenómeno natural, en proporciones difíciles de apreciar. Evidentemente es mucho menor el caso de los ingresos urbanos, más directamente vinculados con la evolución del mercado interno.

La variable "ingreso" tomada en cuenta en el presente estudio corresponde a la suma de todos los ingresos (monetarios y no monetarios) de cada uno de los miembros

(3) A manera de ejemplo, el consumo de los hogares sometidos a la encuesta de 1993 en Madagascar no representa sino un tercio del consumo privado resultado de las cuentas nacionales correspondientes al mismo período. 
del hogar, con excepción de los ingresos de capital. Comprende el conjunto de las remuneraciones del trabajo en la actividad principal y en la secundaria, formales e informales, las bonificaciones en especie, las prestaciones sociales y las pensiones. Si prescindir de los ingresos de capital introduce un sesgo en la medición del ingreso total, este no es susceptible a priori de poner en duda los resultados obtenidos, por su poco peso en los países en desarrollo, sobre todo entre los pobres. Para dar fundamento a las comparaciones intertemporales y geográficas, hemos adoptado una línea de pobreza absoluta común a los dos países. De acuerdo con los trabajos clásicos sobre la materia (Ravaillon, 1996), el umbral tomado en cuenta corresponde al monto que permitía alcanzar una norma de consumo alimentario de 2300 calorías per cápita y por día, al cual se añade un complemento para los gastos no alimentarios. Calculados para 1998, año para el cual disponíamos de encuestas de consumo en ambos países, tales líneas han sido retro y extrapoladas utilizando el índice de precios de consumo correspondiente, ya sea, respectivamente, de 140300 francos malgaches y de 198 nuevos soles, o sea, respectivamente, de 2 y 4 dólares corrientes.

Hacia atrás ambos paneles han sido sistemáticamente controlados y eliminados los datos aberrantes. Hacia adelante el estudio de los sesgos de desgaste ha permitido asegurarse de que los paneles utilizados eran de buena calidad y suficientemente representativos de los universos bajo examen en los dos países. De otro lado, para permitir la comparación se han utilizado en el análisis solamente las variables comunes a las dos series de encuestas. Dichas variables han sido construidas siguiendo definiciones y modos de cálculo rigurosamente idénticos.

\section{POBREZA, CRECIMIENTO Y DESIGUALDAD EN LA SEGUNDA MITAD DE LOS AÑOS 90}

\section{1. Niveles y evolución de la pobreza urbana (1995-2000)}

Entre los años 1995 y 2000 la pobreza ha retrocedido en más de 12 puntos en la capital malgache. Ha pasado así de 86\% a 74\%. Los años 1997 y 2000 constituyen los dos mejores a este respecto. El decrecimiento no sólo se han limitado a la incidencia de la pobreza, sino que afecta al conjunto de los indicadores FGT, en particular la intensidad y severidad de la pobreza (P1 y P2), donde es aún más espectacular (-16 puntos en 5 años). Este importante descenso es tanto más apreciable por cuanto se trata de una verdadera inversión de la tendencia, ya que la pobreza no ha hecho sino agravarse a largo plazo, es decir, al menos desde el comienzo de los años 70. A pesar de esta mejora, casi tres nativos de Tananarivo de cuatro seguían siendo pobres en el 2000. En el caso del Perú, la tendencia es menos clara. Después de una fase de fuerte descenso de la pobreza de 6 puntos entre 1994 y 1997, esta se estabiliza en el período posterior (1997-1999). La ligera disminución de 2 puntos observada entre 1997 y 1998, como tampoco el nuevo aumento que se da en el año siguiente, son estadísticamente significativos.

En niveles, la incidencia comparada de la pobreza urbana en los dos países permite poner claramente en evidencia la distancia que los separa a este respecto. La diferencia era de 50 puntos a mediados de los años 90. A pesar del excepcional 
dinamismo de la economía malgache, aquella aún era de 47 puntos en 1999. Ello significa que a este ritmo habrá que esperar cerca de 20 años para llegar al actual nivel registrado en el Perú.

Cuadro 3 - Evolución de la pobreza monetaria, 1995-2000.

\begin{tabular}{|c|c|c|c|c|c|c|c|c|c|c|}
\hline & \multicolumn{7}{|c|}{ Madagascar } & \multicolumn{4}{|c|}{ Perú } \\
\hline & 1995 & 1996 & 1997 & 1998 & 1999 & 2000 & 1994 & 1997 & 1998 & 1999 \\
\hline $\mathbf{P}_{\mathbf{0}}$ & 85,8 & 85,6 & 80,5 & 79,6 & 77,3 & 73,6 & 35,9 & 30,2 & 28,6 & 30,3 \\
& {$[82,6-$} & {$[82,9-$} & {$[78,1-$} & {$[77,3-$} & {$[74,8-$} & {$[70,3-$} & {$[32,6-$} & {$[27,8-$} & {$[25,7-$} & {$[27,2-$} \\
& $89,0]$ & $88,2]$ & $83,0]$ & $81,8]$ & $79,9]$ & $76,8]$ & $39,3]$ & $32,5]$ & $31,5]$ & $33,5]$ \\
$\mathbf{P}_{1}$ & 52,5 & 50,7 & 44,7 & 44,3 & 42,6 & 36,1 & 12,5 & 10,4 & 10,4 & 10,2 \\
& {$[49,1-$} & {$[48,1-$} & {$[42,7-$} & {$[42,2-$} & {$[40,5-$} & {$[33,6-$} & {$[10,9-$} & {$[9,4-$} & {$[8,9-$} & {$[8,8-$} \\
& $55,8]$ & $53,2]$ & $46,7]$ & $46,4]$ & $44,7]$ & $38,7]$ & $14,0]$ & $11,3]$ & $11,8]$ & 11,6 \\
$\mathbf{P}_{2}$ & 36,7 & 34,8 & 29,3 & 29,3 & 28,1 & 21,8 & 6,0 & 5,1 & 5,4 & 5,2 \\
& {$[33,7-$} & {$[32,6-$} & {$[27,6-$} & {$[27,5-$} & {$[26,3-$} & {$[19,8-$} & {$[5,1-$} & {$[4,5-$} & {$[4,4-$} & {$[4,1-$} \\
& $36,9]$ & $30,9]$ & $31,1]$ & $39,7]$ & $29,9]$ & $23,8]$ & $6,9]$ & $5,6]$ & $6,3]$ & $5,8]$ \\
& & & & & & & & & & \\
\hline
\end{tabular}

Fuentes: Encuestas-empleo 1995-2000, MADIO, Eniv 1994, Enaho 1997-1999, nuestros propios cálculos. Intervalos de confianza al $5 \%$ entre paréntesis.

El examen de la evolución de la pobreza extrema, cuyo umbral, recordémoslo, corresponde a un monto que permite procurarse sólo la dieta de subsistencia, refuerza el diagnóstico anterior. En 1995, el 61\% de los habitantes de Tananarivo vivían en esta situación de privación extrema. Su proporción no ha cesado de disminuir para llegar al $39 \%$ en el 2000. La intensidad y severidad de la extrema pobreza han seguido tendencias similares: ambas se han reducido a la mitad en el período (de 30 a $15 \%$ en el caso de P1, y de 18 a 8\% en el de P2). En el Perú no se ha producido ningún cambio entre 1994 y 1999. La incidencia de la extrema pobreza es allí del orden de $9 \%$, esto es $3 \%$ en cuanto a la intensidad y un poco más de $1 \%$ en cuanto a la severidad. A fines del período, la incidencia de la extrema pobreza era siempre 5 veces más alta en Madagascar que en el Perú.

La yuxtaposición de las funciones de distribución del ingreso per cápita (expresadas en términos reales) ofrece una visualización gráfica de las evoluciones en curso. Permite en particular aliviar la limitación impuesta por la elección de línea de pobreza, por naturaleza arbitraria. El gráfico 1 ilustra claramente la disminución de la pobreza en ambos países. Las curvas se desplazan hacia la derecha de un año a otro en Madagascar (salvo en 1995 y 1996, cuando se entrecruzan), sobre todo en la franja comprendida entre los umbrales de extrema pobreza (límite inferior) y de pobreza (límite superior). En el Perú se distinguen dos grupos de años: 1994, en que la situación es la menos favorable, y 1997-1999, en que la posición relativa de las distribuciones varía según la línea considerada. 
Gráfico 2 - Función de distribución de los ingresos per cápita, 1995-2000.

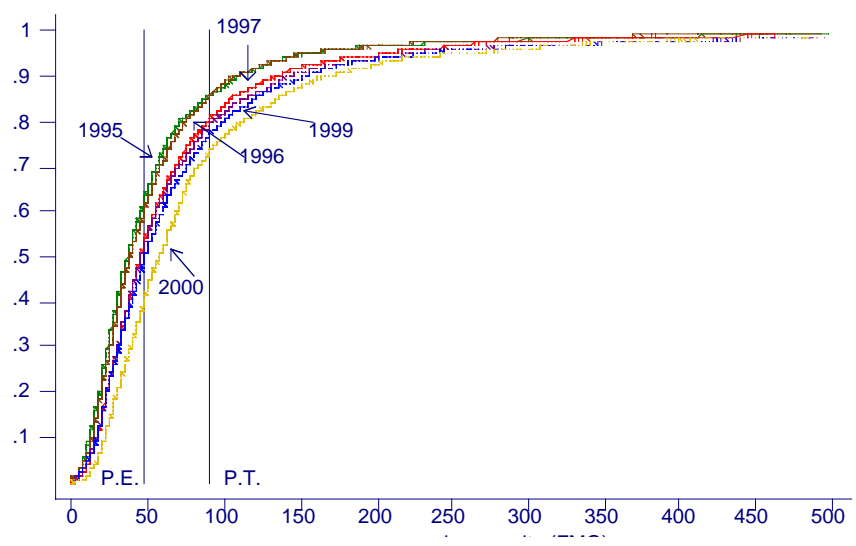

ingreso real per cápita (FMG)

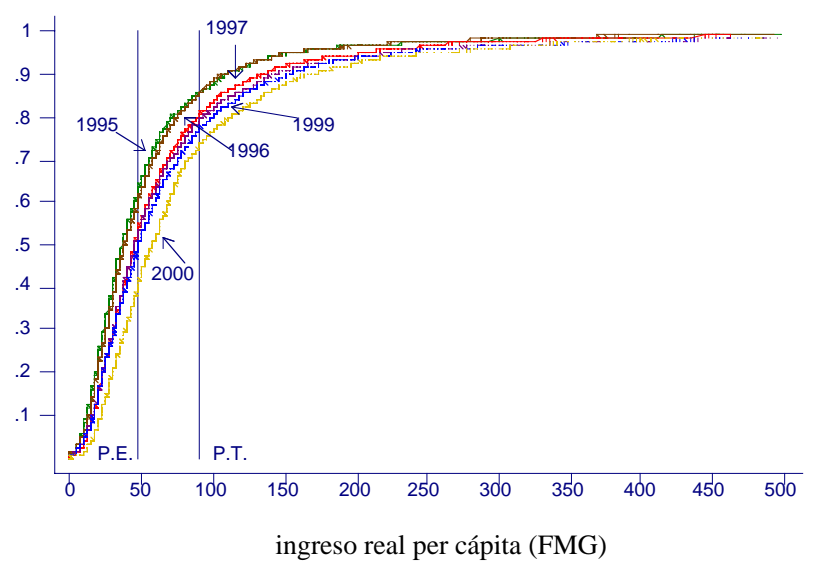

Fuentes: Encuestas-empleo 1995-2000, MADIO, Enniv 1994, Enaho 1997-1999, nuestros propios cálculos.

El análisis en términos de dominancia estocástica, basado en la comparación de funciones de distribución que aparecen arriba, permite poner a prueba la solidez de las conclusiones precedentes, independientemente de la línea de pobreza elegida. En Madagascar refuerza el diagnóstico de sustancial regresión de la pobreza en todo el período. En el umbral del 5\% los tests de Kolmogorov-Smirnov muestran que, en cada año, la distribución del ingreso per cápita "domina" la de los años anteriores, con la única excepción de los años 1997 y 1998, respecto a los cuales no es posible rechazar la hipótesis de igualdad de las distribuciones. En otros términos, la incidencia de la pobreza baja sistemáticamente de manera estadísticamente significativa de un año a 
otro, y ello cualquiera que sea el umbral de pobreza que se considere. Se encuentra nuevamente, por lo demás, en el conjunto de la distribución de los ingresos, la desvinculación observada en el caso de la incidencia de la pobreza en 1997 y 2000 . La mejora de la situación de los hogares afecta por lo demás al conjunto de la condiciones de vida, tanto si se las aprecia desde el punto de vista monetario (ingresos, consumo) como no monetario (confort de la vivienda, acceso a los servicios públicos, escolarización, etc.) (Razafindrakoto \& Roubaud, 1999). En el Perú la constatación es más ambigua. Si la distribución de 1994 se halla significativamente "dominada" (al $5 \%$ ) por las de los años 1997-1999, lo cual significa que la incidencia de la pobreza ha bajado, el diagnóstico sobre estos tres años no permite diferenciarlos.

Cuadro 4 - Evolución de la pobreza: tests de dominancia estocástica de primer orden, 1995-2000.

\begin{tabular}{|c|c|c|c|c|c|c|c|}
\hline & \multicolumn{7}{|c|}{ Madagascar } \\
\hline Perú & $\mathbf{1 9 9 4}$ & $\mathbf{1 9 9 5}$ & $\mathbf{1 9 9 6}$ & $\mathbf{1 9 9 7}$ & $\mathbf{1 9 9 8}$ & $\mathbf{1 9 9 9}$ & $\mathbf{2 0 0 0}$ \\
\hline $\mathbf{1 9 9 4}$ & - & - & - & - & - & - & - \\
$\mathbf{1 9 9 5}$ & - & - & M & M & M & M & M \\
$\mathbf{1 9 9 6}$ & - & - & - & M & M & M & M \\
$\mathbf{1 9 9 7}$ & P & - & - & - & ns & M & M \\
$\mathbf{1 9 9 8}$ & P & - & - & ns & - & M & M \\
$\mathbf{1 9 9 9}$ & P & - & - & ns & ns & - & M \\
$\mathbf{2 0 0 0}$ & - & - & - & - & - & - & - \\
\hline
\end{tabular}

Fuentes: Encuestas-empleo 1995-2000, MADIO, Enniv 1994, Enaho 1997-1999, nuestros propios cálculos.

Lectura: los resultados en el caso del Perú (P) están bajo la primera diagonal, los de Madagascar (M) encima. M: la distribución acumulada del año t (en la columna) domina la del año t-n (en línea); e inversamente en el caso del P. Tests de Kolmogorov-Smirnov significativos al 5\%.

\section{2. Pobreza, crecimiento y desigualdades}

La evolución de la pobreza debe ser vinculada con la dinámica del crecimiento y de las desigualdades. Globalmente, la segunda mitad de los años 90 corresponde a una fase de crecimiento en ambos países, muy fuerte en Madagascar y más errática en el Perú. El ingreso real per cápita de los hogares ha aumentado en $50 \%$ en la capital malgache y en $25 \%$ en las zonas urbanas del Perú. Paralelamente, no se dibuja ninguna tendencia clara en el frente de las desigualdades. En el Perú hasta 1998 aumenta el coeficiente de Gini, pero las variaciones no son significativas. En conjunto los niveles son comparables en los dos países, y se sitúan alrededor del 0,50. Esta cifra muestra la marca de sociedades de una enorme desigualdad, cosa que se halla también a nivel continental: África y América Latina son las dos regiones del mundo en las que las desigualdades son las más fuertes. 
La comparación de los agregados macroeconómicos y de los datos de encuestas muestra hasta qué punto los primeros no reflejan bien, o reflejan mal, la real dinámica a nivel de los hogares. Las desviaciones son particularmente flagrantes en el caso de Madagascar. Mientras que el PIB per cápita aumentó en 2,3\% entre 1995 y 2000, los habitantes de Tananarivo registraron un aumento de $50 \%$ de su poder de compra. Esta divergencia es resultado de la combinación de dos factores, Por una parte es probable que la capital malgache haya aprovechado más que toda otra región del país el cambio favorable de la coyuntura económica (implantación de empresas francas, alza de los salarios, etc.). Pero por otra parte esta divergencia resulta en gran parte de la lamentable calidad de las cuentas nacionales, cuya confiabilidad es más que dudosa (Razafindrakoto \& Roubaud, 1999). En el Perú, en cambio, la evolución macro-económica es más coherente con los resultados aportados por las encuestas. De 1994 a 1999 el PBI per cápita muestra un crecimiento de $13,8 \%$, contra $24,4 \%$ en el ingreso per cápita en los hogares urbanos. Esta vez se puede razonablemente suponer que la desviación es imputable a diferencias reales en las dinámicas urbanas y nacionales, en beneficio de las ciudades, más que a errores de medición en las cifras oficiales.

La evolución de la pobreza puede descomponerse entre un efecto vinculado con el crecimiento de los ingresos, y otro resultante de la variación de las desigualdades. Trataremos, pues, de verificar aquí si las variaciones de la pobreza de un período a otro se deben a puros efectos de crecimiento o si son también imputables a cambios distributivos; o sea, en otros términos, en qué medida se han beneficiado los pobres con el crecimiento. Para responder a esta pregunta, seguiremos el método propuesto por Mahmoudi (1998), el cual, a diferencia de los anteriores trabajos de Datt \& Ravallion (1992), presenta la ventaja de proporcionar una decomposición exacta de ambos efectos, sin término residual. Nos limitaremos al análisis de la variación de la incidencia de la pobreza (Po). Esa decomposición sigue la fórmula siguiente:

$\mathrm{P}_{\mathrm{t}+\mathrm{n}}-\mathrm{P}_{\mathrm{t}}=\left[\mathrm{P}\left(\mathrm{cdf}_{2}, \mathrm{z}\right)-\mathrm{P}\left(\mathrm{cdf}_{1}, \mathrm{z}\right)\right]=\mathrm{cdf}_{1}\left(\mathrm{zm}_{\mathrm{t}} / \mathrm{m}_{\mathrm{t}+\mathrm{n}}\right)-\mathrm{cdf}_{1}(\mathrm{z})$

Donde:

cdf es la función de densidad cumulada

z es la línea absoluta de pobreza

m es el ingreso promedio per cápita

En Madagascar el continuo aumento del poder de compra promedio de los hogares ha favorecido el retroceso de la incidencia de la pobreza. En cambio, el efecto redistributivo varía según los años. El aumento de las desigualdades en 1997, 1998 y, en menor medida, en 2000, viene a contrarrestar la dinámica del crecimiento. Las tensiones hacia la desigualdad son sin embargo demasiado débiles como para contrarrestar el efecto de crecimiento. En total, en el conjunto del período, ambos factores han contribuido conjuntamente a la reducción de la pobreza. Pero de los 12,2 puntos de disminución observada, cerca del $97 \%$ son atribuibles al crecimiento de los ingresos, correspondiendo el 3\% restante un ligero descenso de las desigualdades. Así pues, si se tiene en cuenta el nivel relativamente elevado de las desigualdades, existe un margen de maniobra importante para políticas públicas más redistributivas. En el 
Perú, las evoluciones son más contrastadas. De 1994 a 1997, luego de 1997 a 1998, la caída de la pobreza se asocia con un aumento paralelo de los ingresos. Pero este se ve parcialmente contrapesado por un efecto de redistribución negativa. En 1999 el descenso del ingreso promedio ha repercutido integralmente sobre los pobres, ya que el efecto distributivo era neutro.

En conclusión, pueden extraerse dos resultados interesantes. En cada uno de los períodos considerados, el crecimiento ejerce un efecto positivo en la reducción de la pobreza. En promedio, la elasticidad aparente de la pobreza respecto al crecimiento es de $+0,25$ en Madagascar (un aumento de 4\% del ingreso promedio acarrea una reducción de 1 punto porcentual en la incidencia de la pobreza), y de +0,20 en el Perú. Si bien esta relación puede parecer poco sólida en razón del bajo número de casos observados, viene a confirmar lo obtenido por los numerosos estudios que han establecido un fuerte vínculo entre crecimiento y pobreza (Ravallion \& Chen, 1997; Roemer \& Gugerty, 1997; Dollar \& Kray, 2000). Más aún, la elasticidad que obtenemos en el caso de los dos países es del mismo orden que la estimada econométricamente por Squire (1993) a partir de una amplia muestra de países $(0,24)$. Por otra parte, el crecimiento tiende a generar tensiones desigualitarias, actuando ambos efectos más bien en sentido inverso. Todo sucede como si existiese una "fuerza de inercia redistributiva" que limita el impacto del descenso de los ingresos sobre la pobreza. Es difícil poner en evidencia los complejos mecanismos actuantes, pero seguramente tienen que ver más con las estrategias individuales o los ajustes del mercado (comportamiento de la oferta de trabajo, dinámica de precios y salarios, etc.) que con políticas voluntariamente correctoras por parte del Estado, tan deficientes como son.

\section{Cuadro 5 - Descomposición de la evolución de la pobreza: crecimiento y desigualdad, 1995-2000.}

\begin{tabular}{|l|c|c|c|c|c|c|c|c|c|c|}
\hline & \multicolumn{7}{|c|}{ Madagascar } & \multicolumn{4}{c|}{ Perú } \\
\cline { 2 - 10 } & 1995 & 1996 & 1997 & 1998 & 1999 & 2000 & 1994 & 1997 & 1998 & 1999 \\
\hline Creci- & 100 & 100,7 & 124,9 & 132,5 & 135,3 & 149,9 & 100 & 123,4 & 128,6 & 124,4 \\
miento & & & & & & & & & & \\
& 0,49 & 0,47 & 0,49 & 0,51 & 0,50 & 0,46 & 0,45 & 0,48 & 0,51 & 0,50 \\
Gini & {$[0,47-$} & {$[0,45-$} & {$[0,47-$} & {$[0,49-$} & {$[0,49-$} & {$[0,45-$} & {$[0,43-$} & {$[0,46-$} & {$[0,47-$} & {$[0,47-$} \\
& $0,51]$ & $0,49]$ & $0,51]$ & $0,53]$ & $0,52]$ & $0,48]$ & $0,48]$ & $0,50]$ & $0,54]$ & $0,54]$ \\
Creci- & - & $-0,1 \mathrm{pts}$ & $-6,3 \mathrm{pts}$ & $-2,1 \mathrm{pts}$ & $-1,0 \mathrm{pts}$ & $-3,9 \mathrm{pts}$ & - & $-10,1 \mathrm{pts}$ & $-2,3 \mathrm{pts}$ & $+1,7 \mathrm{pts}$ \\
miento & & & & & & & & & & \\
Desigual- & - & $-0,1 \mathrm{pts}$ & $+1,2 \mathrm{pts}$ & $+1,2 \mathrm{pts}$ & $-1,3 \mathrm{pts}$ & $+0,2 \mathrm{pts}$ & - & $+4,4 \mathrm{pts}$ & $+0,7 \mathrm{pts}$ & $0,0 \mathrm{pts}$ \\
dad & & & & & & & & & & \\
Variación & - & $-0,2 \mathrm{pts}$ & $-5,1 \mathrm{pts}$ & $-0,9 \mathrm{pts}$ & $-2,3 \mathrm{pts}$ & $-3,7 \mathrm{pts}$ & - & $-5,7 \mathrm{pts}$ & $-1,6 \mathrm{pts}$ & $+1,7 \mathrm{pts}$ \\
\hline
\end{tabular}

Fuentes: Encuestas-empleo 1995-2000, MADIO, Eniv 1994, Enaho 1997-1999, nuestros propios cálculos. Intervalos de confianza al 5\% entre paréntesis. 


\section{DINÁMICA INDIVIDUAL DE LA POBREZA 1997-1999}

\section{1. Las transiciones de pobreza}

En Madagascar, en un contexto de disminución cada vez más rápida de la pobreza, un poco más del $10 \%$ de los individuos salen de ella cada año. Pero recíprocamente, entre un tercio y más del $40 \%$ de los no pobres entran en situación de pobreza el año siguiente, lo cual muestra que el hecho de no ser identificado como pobre en un momento dado no garantiza en nada la permanencia en esta situación favorable a lo largo de un período más largo. En el Perú, donde la coyuntura registra una primera fase de reducción de la pobreza, seguida por una fuerte degradación al año siguiente, las transiciones hacia la pobreza o hacia fuera de ella son igualmente intensas. Esta vez, se trata de casi el $40 \%$ de los pobres que escapa a su condición cada año, mientras que del $13 \%$ al $20 \%$ efectúan el trayecto en sentido inverso. En ambos casos, las matrices de transición muestran estructuras sorprendentemente estables en cada país a lo largo del tiempo, aun si el aumento (el descenso) global de la pobreza tiende a aumentar (reducir) los flujos de entrada (de salida), y a limitar la salida de ella (a la entrada). En total, el 17\% de los individuos cambian de categoría de pobreza en Madagascar cada año. Estos "tránsfugas" representan incluso entre un cuarto y un quinto de la población peruana.

Cuadro 6 - Matrices de transición de pobreza 1997-1999.

Madagascar

\begin{tabular}{|c|c|c|c|}
\hline & \multicolumn{3}{|c|}{1998} \\
\hline 1997 & Pobre & No pobre & Total \\
\hline Pobre & 88,7 & 11,3 & $\begin{array}{c}100 \\
(81,2)\end{array}$ \\
\hline No pobre & 2,7 & 57,3 & $\begin{array}{c}100 \\
(18,8) \\
\end{array}$ \\
\hline Total & 80,1 & 19,9 & 100 \\
\hline
\end{tabular}

\begin{tabular}{|c|c|c|c|}
\hline & \multicolumn{3}{|c|}{1999} \\
\hline 1998 & Pobre & No pobre & Total \\
\hline Pobre & 87,6 & 12,4 & $\begin{array}{c}100 \\
(80,1)\end{array}$ \\
\hline No pobre & 33,5 & 66,5 & $\begin{array}{c}100 \\
(19,9)\end{array}$ \\
\hline Total & 76,9 & 23,1 & 100 \\
\hline
\end{tabular}

Perú

\begin{tabular}{|c|c|c|c|}
\hline & \multicolumn{3}{|c|}{1998} \\
\hline 1997 & Pobre & No pobre & Total \\
\hline Pobre & 62,4 & 37,6 & $\begin{array}{c}100 \\
(29,2)\end{array}$ \\
\hline No pobre & 13,6 & 86,4 & $\begin{array}{c}100 \\
(70,8)\end{array}$ \\
\hline Total & 27,9 & 72,1 & 100 \\
\hline
\end{tabular}

\begin{tabular}{|c|c|c|c|}
\hline & \multicolumn{3}{|c|}{1999} \\
\hline 1998 & Pobre & No pobre & Total \\
\hline Pobre & 63,0 & 37,0 & $\begin{array}{c}100 \\
(27,9)\end{array}$ \\
\hline No pobre & 19,4 & 80,6 & $\begin{array}{c}100 \\
(72,1)\end{array}$ \\
\hline Total & 31,6 & 68,4 & 100 \\
\hline
\end{tabular}

Fuentes: Encuestas-empleo 1995-2000, MADIO, Enaho 1997-1999, nuestros propios cálculos. 
El diagrama que antecede reconstituye el conjunto de los flujos de ingresos y de salidas de la pobreza en esos tres años. Pone a luz tres resultados interesantes. En primer lugar, da una idea precisa de la complejidad de las transiciones de pobreza, que los datos en cortes transversales no nos permiten captar. En segundo lugar, confirma que el "halo de pobreza" desborda ampliamente la categoría de pobres aprehendida en corte instantáneo. Mientras que la tasa de pobreza en 1999 es de 77\%, el $91 \%$ de los habitantes de Tananarivo han pasado al menos por un período de pobreza en el curso de los dos años anteriores. En el Perú, estas proporciones son respectivamente de $32 \%$ y $48 \%$. Sin embargo, y a pesar de la importancia de estos cambios de estado, queda siempre un núcleo duro de pobreza (pobreza permanente) que se puede estimar, en lo que respecta a los tres años del panel del cual disponemos, en $13 \%$ en el Perú y en $65 \%$ en Madagascar. En fin, aparece de todo ello que el fenómeno de la pobreza constituye un proceso con memoria. El hecho de haber caído en situación de pobreza en un momento dado acrecienta la probabilidad de permanecer en ella, e inversamente. Así, en 1999 en ambos países la probabilidad de seguir siendo pobre era superior en 24 puntos según se hubiese sido ya pobre, o no, en 1997 (respectivamente $71 \%$ y 47\% en el Perú y $90 \%$ y $66 \%$ en Madagascar). Simétricamente, los individuos no pobres en 1998 tienen sensiblemente más probabilidades de mantenerse fuera de la pobreza al año siguiente, si eran ya no pobres en 1997. La diferencia de probabilidades era de 28 puntos en el Perú (respectivamente $85 \%$ y 57\%) e incluso alcanzaba 40 puntos en Madagascar (85\% y 45\%). Se pueden invocar dos interpretaciones, no necesariamente en competencia, para explicar el fenómeno. Por una parte, el hecho de ser identificado temporalmente como pobre podría desempeñar un papel de "señal" que permite descubrir hogares estructuralmente frágiles (inestabilidad familiar o profesional, salud precaria, etc.). Por otra parte, experimentar episodios de pobreza puede tornar frágiles los hogares (descolarización, enfermedad, inversión deficiente, aversión al riesgo) y arrastrarlos a verdaderas trampas de pobreza de las cuales es difícil escapar. Tendremos ocasión de verificar estas hipótesis en la parte siguiente. 
Gráfico 3 - Flujo ingreso y salida de la pobreza entre 1997 y 1999.



Total 1999

Panel nacional, 1717 hogares. ENAHO 97. 98. 99.

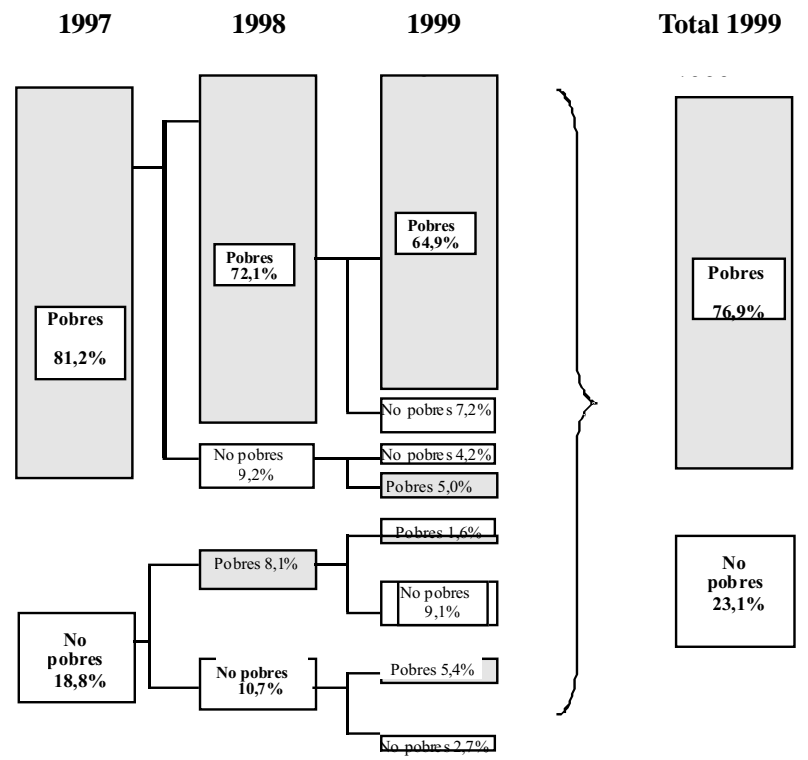

Panel nacional, 1214 hogares. MADIO 97. 98. 99.

Fuentes: Paneles, Encuestas-empleo 1997-1999, MADIO, Enabo 1997-1999, nuestros propios cálculos. 
La movilidad entre pobreza y no pobreza no es, en nada, específica de nuestros dos países. Una publicación reciente del Banco Mundial (2000) ha compilado una decena de estudios recurriendo a paneles de hogares que dan la distribución entre pobreza permanente y pobreza transitoria en diferentes países en desarrollo o en transición. Es posible, por tanto, compararlos con nuestros resultados. Incluso si los niveles de pobreza no son comparables en los diferentes países, por causa de la elección de líneas de pobreza no armonizadas, así como de una cobertura geográfica variable de acuerdo a los países, en todos los casos se hace evidente que la pobreza transitoria constituye una parte sustancial de la pobreza (cuadro 7). Con excepción de Madagascar, y en menor medida de Costa de Marfil, la incidencia de la pobreza transitoria es sistemáticamente más alta que la de la pobreza permanente, en una relación que varía de 1 a 1,2 en Etiopía, hasta una de 1 a 9 en Pakistán. El núcleo duro de la pobreza será más reducido cuando el panel considerado sea más corto. La poca importancia relativa del componente transitorio de la pobreza en Madagascar se explica por el nivel de pobreza absoluta, muy superior al registrado en otros países. Como quiera que sea, en todos los casos considerados el hecho de no tomar en cuenta estas dos categorías de pobres implica el riesgo de hacer inoperantes las políticas de lucha contra la pobreza, ya que pueden necesitar instrumentos diferentes para cada una de las dos subpoblaciones.

Cuadro 7- Pobreza permanente y transitoria en diferentes países.

\begin{tabular}{|lcccc|}
\hline \multicolumn{1}{|c}{ Países } & Período & $\begin{array}{c}\text { Pobres } \\
\text { permanentes }\end{array}$ & $\begin{array}{c}\text { Pobres } \\
\text { transitorios }\end{array}$ & $\begin{array}{c}\text { Nunca } \\
\text { pobres }\end{array}$ \\
\hline Madagascar & $1997-99$ & 64,9 & 26,0 & 9,1 \\
Perú & $1997-99$ & 13,0 & 35,2 & 51,8 \\
\hline China & $1985-90$ & 6,2 & 47,8 & 46,0 \\
Costa de Marfil & $1987-88$ & 25,0 & 22,0 & 53,0 \\
Etiopía & $1994-97$ & 24,8 & 30,1 & 45,1 \\
Pakistán & $1986-91$ & 3,0 & 55,3 & 41,7 \\
Rusia & $1992-93$ & 12,6 & 30,2 & 57,2 \\
África del Sur & $1993-98$ & 22,7 & 31,5 & 45,8 \\
Zimbabwe & $1992 / 93-95 / 96$ & 10,6 & 59,6 & 29,8 \\
\hline
\end{tabular}

Fuentes: Attacking Poverty, World Bank 2000 (borrador), p. 21 y nuestras estimaciones para Madagascar y Perú.

\section{2. Análisis de los perfiles de pobreza}

La comparación de los perfiles de pobreza da una primera visión de las características diferenciales de los hogares de acuerdo con su estatus frente a la pobreza. A partir del panel cilíndrico de hogares 1997-1999, hemos construido tres conjuntos de hogares: los "pobres permanentes" (pobres los tres años), los "pobres transitorios" 
(pobres por uno o dos años) y los "nunca pobres". Las variables han sido clasificadas en tres grandes grupos: las que tienen que ver con el jefe del hogar, las que se relacionan con la estructura del hogar y, en fin, las que se vinculan con el barrio de residencia. Tales variables son medidas en el año de base, es decir 1977. Esta primera aproximación descriptiva se acompaña con tests estadísticos, a fin de apreciar la significatividad de las diferencias observadas en las distribuciones.

La primera constatación que se puede derivar del cuadro 8 es la notable similitud de las características sociodemográficas de la muestra en ambos países. La dimensión de los hogares es ligeramente mayor en Madagascar (5,8 contra 5,4 en el Perú) y la población un poco más joven y menos educada. La juventud relativa de los habitantes de Tananarivo se traduce en términos del empleo por una tasa de dependencia (ratio inactivo/activo) ligeramente más alta en Madagascar. La estructura del empleo diferencia bastante a los dos países. Los empleos son más calificados en el Perú (proporción de trabajadores calificados), el sector industrial más desarrollado, mientras que la capital malgache se halla marcada por la masiva preponderancia de los servicios y del sector informal. Paradójicamente, las actividades agrícolas periurbanas pesan más en el empleo en el caso del Perú, pero esto se explica sin duda por la presencia en la muestra peruana de ciudades secundarias, mientras que en Madagascar sólo la capital forma parte de ella. De hecho, es en el plano del tipo de vivienda y del acceso a los servicios públicos de infraestructura que se hacen visibles las diferencias más importantes. Estos indicadores reflejan claramente los niveles de desarrollo desiguales de los dos países, en particular el acumulado retraso a largo plazo en materia de inversión pública en Madagascar. Mientras que más de nueve hogares de cada diez tienen acceso a la electricidad y tres cuartas partes disfrutan de acceso a la red pública de agua potable en el Perú, estas proporciones no son más que de $60 \%$ y $14 \%$, respectivamente, en la sociedad malgache.

Si ahora ponemos atención en las variables asociadas con las diferentes formas de pobreza, se puede distinguir las que actúan de manera similar en los dos países, y las que se relacionan con especificidades nacionales. En los dos países el tamaño de la familia, el peso relativo que representan los niños pequeños, la edad del jefe, lo limitado de su nivel educativo y más ampliamente del stock de capital humano del conjunto de los miembros del hogar, son otros tantos factores que aumentan la incidencia de la pobreza, y, en el seno de esta, la probabilidad de pobreza crónica. El tipo de vivienda y el acceso a las infraestructuras básicas (agua y electricidad) discriminan igualmente muy bien las tres categorías de hogares. En fin, la tasa de dependencia económica, la proporción del empleo público y la tasa de equipamiento de los hogares están significativamente vinculados (positivamente en el primer caso, y negativamente en el segundo) con el estatus frente a la pobreza. De manera menos evidente, encontramos que las distintas formas de pobreza se diferencian en función del barrio de residencia. Los pobres tienden a vivir en los barrios desfavorecidos: tanto en términos de las características individuales (el ingreso promedio de los residentes es más bajo, la tasa de informalidad es más elevada) como en términos de los servicios públicos (acceso al agua, a la electricidad, etc.). En las áreas urbanas peruanas y en la capital malgache, el fenómeno de la pobreza tiene un fuerte componente espacial. Para profundizar este 
punto habría que identificar el sentido de la causalidad: puede ser que los pobres hayan sido conducidos a reagruparse en los barrios pobres o, más bien, quizá el hecho de residir en un barrio pobre refuerza o conduce a la pobreza. Este tema será abordado en la próxima sección. Pasemos ahora de los factores comunes a las diferencias. En el Perú los hombres parecen disponer relativamente de ventajas, mientras que el sexo del jefe de familia no importa en Madagascar, sociedad más igualitaria desde el punto de vista del género. Pero el resultado más interesante es el papel del empleo privado respecto a la pobreza. Así, en ambos países, cuanto más insertados se hallan los jefes de familia en el sector informal, más pobres son (e inversamente en lo que respecta al sector privado formal). Más aún, en Madagascar ambas variables permiten también distinguir claramente las dos formas de pobreza, pero tal no es el caso en el Perú, donde no se registra ninguna diferencia significativa entre los pobres transitorios y permanentes. Este resultado podría ser reflejo del intenso movimiento de precarización del empleo asalariado en el sector formal a lo largo de los dos últimos decenios, que ha conducido a una pauperización masiva de los hogares que antes formaban parte de la clase media. En fin, a pesar de que la polarización espacial (respecto a los ingresos de los residentes) es menos pronunciada en Madagascar que en el Perú, las características del barrio de residencia son más discriminantes en Madagascar que en el Perú, al menos para diferenciar la pobreza crónica de la pobreza transitoria. Este fenómeno no se explica a priori por una más baja mixidad social en la capital malgache si no más bien por la indigencia de las políticas de infraestructuras urbanas, bastante más polarizadas en Madagascar.

Cuadro 8 - Perfiles de pobreza de acuerdo al tipo de pobreza.

\begin{tabular}{|c|c|c|c|c|c|c|c|c|}
\hline & \multirow[b]{2}{*}{$\begin{array}{c}\text { Pobre } \\
\text { perma- } \\
\text { nente }\end{array}$} & \multicolumn{3}{|c|}{ Madagascar } & \multicolumn{4}{|c|}{ Perú } \\
\hline & & $\begin{array}{c}\text { Pobre } \\
\text { transi- } \\
\text { torio }\end{array}$ & $\begin{array}{l}\text { Jamás } \\
\text { Pobre }\end{array}$ & Total & Total & $\begin{array}{c}\text { Pobre } \\
\text { perma- } \\
\text { nente }\end{array}$ & $\begin{array}{c}\text { Pobre } \\
\text { transi- } \\
\text { torio }\end{array}$ & $\begin{array}{c}\text { Jamás } \\
\text { pobre }\end{array}$ \\
\hline Total & 64,9 & 26,0 & 9,0 & 100 & 100 & 12,5 & 32,7 & 54,8 \\
\hline \multicolumn{9}{|l|}{$\begin{array}{c}\text { Jefe del } \\
\text { hogar }\end{array}$} \\
\hline $\begin{array}{l}\text { Edad } \\
\text { Sexo }\end{array}$ & $43,9 * * *$ & $46,7+++$ & 47,6 & 44,9 & 47,5 & $43,5 * * *$ & $47,6+++$ & 48,3 \\
\hline Hombre & 86,2 & $83,6^{*}$ & 89,8 & 85,9 & 83,6 & $76,5 * *$ & $84,6++$ & 84,6 \\
\hline $\begin{array}{l}\text { Mujer } \\
\text { Nivel de } \\
\text { educación }\end{array}$ & 13,8 & 16,4 & 10,2 & 14,1 & 16,4 & 23,5 & 15,4 & 15,4 \\
\hline $\begin{array}{l}\text { Sin nivel/ } \\
\text { primaria }\end{array}$ & $51,6^{* * *}$ & $27,4 * * *+++$ & 10,0 & 41,5 & 35,2 & $48,4 * * *$ & $46,4 * * *$ & 25,5 \\
\hline Secundaria & 45,6 & $52,8 * *$ & 38,4 & 46,8 & 40,8 & 45,1 & 43,5 & 38,3 \\
\hline Universitario & $2,8 * * *$ & $19,9 * * *+++$ & 51,6 & 11,7 & 24,0 & $6,5 * * *$ & $10,0 * * *$ & 36,3 \\
\hline Experiencia & $31,7 * *$ & $31,6^{*}$ & 28,4 & 31,4 & 33,3 & 31,2 & $34,9 * *++$ & 32,8 \\
\hline
\end{tabular}




\begin{tabular}{|c|c|c|c|c|c|c|c|c|}
\hline & \multicolumn{4}{|c|}{ Madagascar } & \multicolumn{4}{|c|}{ Perú } \\
\hline & $\begin{array}{c}\text { Pobre } \\
\text { perma- } \\
\text { nente }\end{array}$ & $\begin{array}{c}\text { Pobre } \\
\text { transi- } \\
\text { torio }\end{array}$ & $\begin{array}{l}\text { Jamás } \\
\text { Pobre }\end{array}$ & Total & Total & $\begin{array}{c}\text { Pobre } \\
\text { perma- } \\
\text { nente }\end{array}$ & $\begin{array}{c}\text { Pobre } \\
\text { transi- } \\
\text { torio }\end{array}$ & $\begin{array}{l}\text { Jamás } \\
\text { pobre }\end{array}$ \\
\hline $\begin{array}{l}\text { Estatus } \\
\text { matrimon. }\end{array}$ & & & & & & & & \\
\hline Casado & $76,2 * *$ & $73,8 * *$ & 83,9 & 76,3 & 60,0 & $49,7 * * *$ & $56,4 * *$ & 64,4 \\
\hline Unión libre & $7,4 * * *$ & $3,5++$ & 1,4 & 5,8 & 19,8 & $26,2 * *$ & $27,2^{* * * *}$ & 13,8 \\
\hline $\begin{array}{l}\text { Soltero/viudo } \\
\text { /divorciado } \\
\text { CSP }\end{array}$ & 16,4 & $22,6^{*}$ & 14,8 & 17,9 & 20,2 & 24,0 & $16,4^{* *}+$ & 21,8 \\
\hline $\begin{array}{l}\text { Ejecutivo/ } \\
\text { patrón }\end{array}$ & $11,0 * * *$ & $26,8^{* * *}$ & 68,0 & 19,8 & 30,7 & $7,1 * * *$ & $19,3 * * *+++$ & 42,9 \\
\hline $\begin{array}{l}\text { No ejecutivo } \\
\text { /obrero }\end{array}$ & $45,7 * * *$ & $41,2 * * *$ & 22,1 & 42,7 & 32,1 & 33,9 & $41,3 * * *$ & 26,0 \\
\hline $\begin{array}{l}\text { Independiente } \\
\text { PEA }\end{array}$ & $43,3^{* * * *}$ & $31,3^{* * *}$ & 9,9 & 37,5 & 37,2 & $59,0 * * *$ & $39,4 * *+++$ & 31,1 \\
\hline Ocupado & & & & & 80,6 & 77,0 & 82,6 & 80,2 \\
\hline Desocupado & & & & & 4,0 & 4,6 & 4,3 & 3,7 \\
\hline Inactivo & & & & & 15,4 & 18,4 & 13,1 & 16,1 \\
\hline $\begin{array}{l}\text { Sector } \\
\text { instituc. }\end{array}$ & & & & & & & & \\
\hline Público & $17,1 * * *$ & $27,6+++$ & 37,5 & 21,4 & 12,1 & $4,6^{* * * *}$ & $8,7 * * *$ & 16,0 \\
\hline Priv. formal & $27,2 * * *$ & $35,8 * * *+++$ & 50,4 & 31,3 & 36,1 & $22,7 * * *$ & $26,2 * * *$ & 45,2 \\
\hline $\begin{array}{l}\text { Informal } \\
\text { Rama de } \\
\text { actividad }\end{array}$ & $55,7 * * *$ & $36,6 * * *+++$ & 12,1 & 47,3 & 51,8 & $72,7 * * *$ & $65,1 * * *$ & 38,8 \\
\hline Primario & 8,5 & $3,7++$ & 3,5 & 6,9 & 11,9 & $24,5 * * *$ & $15,9 * * *++$ & 6,6 \\
\hline Secundario & $34,7 * *$ & $33,6^{*}$ & 24,1 & 33,5 & 51,2 & 49,9 & $57,3^{* *}$ & 47,9 \\
\hline $\begin{array}{l}\text { Servicios } \\
\text { Empleo } \\
\text { secundario }\end{array}$ & $56,9 * * *$ & $62,6^{*}$ & 72,5 & 59,6 & 36,9 & $25,6 * * *$ & $26,8 * * *$ & 45,6 \\
\hline $\mathrm{Si}$ & 17,3 & $12,0++$ & 13,2 & 15,6 & 13,3 & $14,4 * *$ & 11,3 & 14,3 \\
\hline No & 82,7 & 88,0 & 86,6 & 84,4 & 86,7 & 85,6 & 88,7 & 85,7 \\
\hline Hogar & & & & & & & & \\
\hline $\begin{array}{l}\text { Tamaño } \\
\text { Compos. } \\
\text { demo. } \\
\text { Nro de } \\
\text { miembros }\end{array}$ & $6,3^{* * *}$ & $5,0^{*}+++$ & 4,5 & 5,8 & 5,4 & $6,6 * * *$ & $6,1 * * *$ & 4,8 \\
\hline $\begin{array}{l}\text { \# miembros } \\
0-9 \text { años }\end{array}$ & $1,89 * * *$ & $1,08 * * *+++$ & 0,70 & 1,57 & 1,2 & $2,1 * * *$ & $1,4 * * *+++$ & 0,9 \\
\hline $\begin{array}{l}\text { \# miembros } \\
10-15 \text { años }\end{array}$ & $1,11 * * *$ & $0,57+++$ & 0,49 & 0,91 & 0,8 & $1,2 * * *$ & $1,0 * * *+$ & 0,5 \\
\hline
\end{tabular}




\begin{tabular}{|c|c|c|c|c|c|c|c|c|}
\hline & \multicolumn{4}{|c|}{ Madagascar } & \multicolumn{4}{|c|}{ Perú } \\
\hline & $\begin{array}{c}\text { Pobre } \\
\text { perma- } \\
\text { nente }\end{array}$ & $\begin{array}{c}\text { Pobre } \\
\text { transi- } \\
\text { torio }\end{array}$ & $\begin{array}{l}\text { Jamás } \\
\text { Pobre }\end{array}$ & Total & Total & $\begin{array}{c}\text { Pobre } \\
\text { perma- } \\
\text { nente }\end{array}$ & $\begin{array}{c}\text { Pobre } \\
\text { transi- } \\
\text { torio }\end{array}$ & $\begin{array}{l}\text { Jamás } \\
\text { pobre }\end{array}$ \\
\hline $\begin{array}{l}\text { \# miembros } \\
16-60 \text { años }\end{array}$ & 3,11 & 3,13 & 3,11 & 3,11 & 3,1 & 3,1 & $3,3 * *$ & 3,0 \\
\hline $\begin{array}{l}\text { \# miembros } \\
\text { + de } 60 \text { años } \\
\text { Estruc. \% }\end{array}$ & 0,17 & $0,27++$ & 0,20 & 0,20 & 0,3 & 0,2 & 0,3 & 0,4 \\
\hline $\begin{array}{l}\% \text { miembros } \\
0-9 \text { años }\end{array}$ & $29,6^{* * *}$ & $19,1 * *+++$ & 14,3 & 25,5 & 20,5 & $31,6 * * *$ & $22,2^{* * *}+++$ & 16,9 \\
\hline $\begin{array}{l}\% \text { miembros } \\
10-15 \text { años }\end{array}$ & $15,9 * * *$ & $9,6+++$ & 8,5 & 13,6 & 13,1 & $18,0 * * *$ & $15,9 * * *$ & 10,4 \\
\hline $\begin{array}{l}\% \text { miembros } \\
16-60 \text { años }\end{array}$ & $50,1 * * *$ & $64,1 * *+++$ & 70,0 & 55,5 & 58,5 & $46,1 * * *$ & $55,0 * * *+++$ & 63,5 \\
\hline $\begin{array}{l}\% \text { miembros } \\
+ \text { de } 60 \text { años } \\
\text { Familia } \\
\text { nuclear }\end{array}$ & $4,4^{*}$ & $7,1++$ & 7,2 & 5,3 & 7,9 & $4,4 * * *$ & $6,8^{*}+$ & 9,3 \\
\hline $\mathrm{Si}$ & 69,7 & 64,1 & 73,0 & 68,6 & 62,4 & 64,7 & $57,4^{*}$ & 64,8 \\
\hline No & 30,3 & 35,9 & 27,0 & 31,4 & 37,6 & 35,3 & 42,6 & 35,2 \\
\hline $\begin{array}{l}\% \text { percep- } \\
\text { tores de } \\
\text { ingreso }\end{array}$ & $37,2 * * *$ & $42,4 * * *+++$ & 53,4 & 40,0 & 47,9 & $32,4 * * *$ & $44,2 * * *+++$ & 53,7 \\
\hline $\begin{array}{l}\text { \% de activos } \\
\text { ocupados }\end{array}$ & $41,4 * * *$ & $45,4 * * *++$ & 55,9 & 43,8 & 46,4 & $34,5 * * *$ & $44,3 * * *+++$ & 50,4 \\
\hline $\begin{array}{l}\text { Tasa de capi- } \\
\text { tal humano } \\
\text { Sector } \\
\text { instituc. }\end{array}$ & $0,36 * * *$ & $0,50 * * *+++$ & 0,63 & 0,42 & 0,49 & $0,39 * * *$ & $0,45^{* * *}+++$ & 0,54 \\
\hline $\begin{array}{l}\text { Empleo púb. } \\
\text { /PET }\end{array}$ & $5,6^{* * * *}$ & $10,8^{* * *}+++$ & 23,8 & 8,6 & 6,9 & $2,1 * * *$ & $5,3 * * *+++$ & 9,0 \\
\hline $\begin{array}{l}\text { Empleo } \\
\text { formal/PET }\end{array}$ & $21,6 * * *$ & $25,5^{* * *}+$ & 35,6 & 23,8 & 22,7 & $15,0 * * *$ & $17,3 * * *$ & 27,7 \\
\hline $\begin{array}{l}\text { Empleo in- } \\
\text { formal/PET }\end{array}$ & $43,5^{* * * *}$ & $26,6 * * *+++$ & 12,7 & 36,3 & 34,6 & $44,8 * * *$ & $42,6^{* * *}$ & 27,5 \\
\hline $\begin{array}{l}\text { Desemple- } \\
\text { ados, inac- } \\
\text { tivos/PET }\end{array}$ & 29,4 & $37,2 * * *+++$ & 27,9 & 31,3 & 35,8 & 38,1 & $34,8+++$ & 35,8 \\
\hline \multicolumn{9}{|l|}{ Vivienda } \\
\hline $\begin{array}{l}\text { Estatus de } \\
\text { ocupación } \\
\text { proprietario } \\
\text { con título }\end{array}$ & $36,8^{* *}$ & $45,1++$ & 48,2 & 40,0 & 72,7 & 71,5 & $67,6^{* *}$ & 76,0 \\
\hline
\end{tabular}




\begin{tabular}{|c|c|c|c|c|c|c|c|c|}
\hline & \multicolumn{3}{|c|}{ Madagascar } & \multicolumn{5}{|c|}{ Perú } \\
\hline & $\begin{array}{c}\text { Pobre } \\
\text { perma- } \\
\text { nente }\end{array}$ & $\begin{array}{c}\text { Pobre } \\
\text { transi- } \\
\text { torio } \\
\end{array}$ & \begin{tabular}{|l} 
Jamás \\
Pobre
\end{tabular} & Total & Total & $\begin{array}{r}\text { Pobre } \\
\text { perma- } \\
\text { nente }\end{array}$ & $\begin{array}{c}\text { Pobre } \\
\text { transi- } \\
\text { torio } \\
\end{array}$ & $\begin{array}{c}\text { Jamás } \\
\text { pobre }\end{array}$ \\
\hline $\begin{array}{l}\text { proprietario } \\
\text { sin título }\end{array}$ & $14,7^{* *}$ & $9,8++$ & 8,1 & 12,8 & 6,2 & 6,3 & $11,2 * * *+$ & 3,2 \\
\hline $\begin{array}{l}\text { Inquilino, } \\
\text { otros }\end{array}$ & 48,5 & 45,1 & 43,7 & 47,2 & 21,1 & 22,1 & 21,1 & 20,8 \\
\hline $\begin{array}{l}\text { Agua } \\
\text { corriente }\end{array}$ & $3,5^{* * *}$ & $23,9 * * *+++$ & 65,9 & 14,5 & 75,1 & $59,5^{* * *}$ & $64,2 * * *$ & 85,2 \\
\hline Electric. & $46,5^{* * *}$ & $81,0^{* * *}+++$ & 96,7 & 60,0 & 92,7 & $80,0 * * *$ & $88,6^{* * *}+$ & 98,0 \\
\hline $\begin{array}{l}\text { Paredes } \\
\text { firmes }\end{array}$ & & & & & 61,6 & $36,9 * * *$ & $48,8^{* * *}+$ & 74,9 \\
\hline $\begin{array}{l}\text { WC en } \\
\text { la casa }\end{array}$ & $1,5 * * *$ & $16,3^{* * *}+++$ & 50,0 & 9,8 & 67,2 & $37,2 * * *$ & $54,0 * * *+++$ & 81,8 \\
\hline $\begin{array}{l}\text { Número de } \\
\text { activos }\end{array}$ & $1,2 * * *$ & $2,4 * * *+++$ & 4,9 & 1,8 & 3,8 & $1,7 * * *$ & $2,6 * * *+++$ & 5,0 \\
\hline \multicolumn{9}{|l|}{ Barrio } \\
\hline $\begin{array}{l}\text { Ingreso } \\
\text { promedio }\end{array}$ & $77,3^{* * *}$ & $95,9 * * *+++$ & 113,7 & 85,5 & 405,6 & $194,9 * * *$ & $280,0 * * *+++$ & 528,7 \\
\hline $\begin{array}{l}\text { Hogares } \\
\text { con agua }\end{array}$ & $10,3^{* * *}$ & $20,9 * * *+++$ & 33,4 & 15,1 & 74,6 & $63,6^{* * *}$ & $64,8^{* * *}$ & 82,9 \\
\hline $\begin{array}{l}\text { Hogares con } \\
\text { electricidad }\end{array}$ & $55,6^{* * *}$ & $70,7 * * *+++$ & 78,9 & 61,7 & 92,2 & $81,4 * * *$ & $89,6 * * *++$ & 96,3 \\
\hline $\begin{array}{l}\text { Tasa de } \\
\text { informal. }\end{array}$ & $53,3 * * *$ & $44,8 * * *+++$ & 38,6 & 49,8 & 50,9 & 64,9 & 58,7 & 43,1 \\
\hline
\end{tabular}

Fuentes: Paneles cilíndricos, Encuestas-empleo 1997-1999, MADIO, Enaho 1997-1999, nuestros propios cálculos.

\section{DETERMINANTES DE LAS TRANSICIONES DE POBREZA}

\section{1. Revisión de los trabajos empíricos}

Como anotan Baulch y Hoddinott, existen muy pocos estudios sobre la dinámica de la pobreza en los países en desarrollo (Baulch \& Hoddinott, 2000: 2) aun cuando ese campo de investigación ha comenzado recientemente a desarrollarse (ver cuadro 9). La mayoría de los trabajos sobre los aspectos intertemporales de la pobreza se sitúan en una óptica de estática comparativa. Ahora bien, Chaudhuri y Ravallion han mostrado que los indicadores estáticos de pobreza no permiten sino de manera muy imperfecta distinguir pobres permanentes de pobres transitorios (Chaudhuri \& Ravallion, 1994). Como ya lo hemos mencionado, la causa principal de esta laguna radica en la ausencia de encuestas longitudinales de hogares en la mayor parte de los países en desarrollo. 
En el cuadro que sigue se registran los diferentes estudios existentes sobre la dinámica de la pobreza en lo que concierne a estos países. Se constata que la mitad de ellos se ocupan de apenas algunos centenares de hogares y alrededor de $40 \%$ no abarca más de dos años. Estas restricciones menguan la robustez de los resultados en el sentido que estos no son representativos de la población estudiada y no pueden identificar propiamente los hogares en situación de pobreza crónica y pobreza transitoria, y no pueden, a fortiori considerar los shocks experimentados por estos hogares.

Esos estudios difieren entre ellos no solamente por la amplitud del período analizado (y el número de olas) sino también por su cobertura geográfica. Divergen también en razón de la diversidad de opciones metodológicas y temas abordados, de manera que no es posible generalizar hoy los resultados empíricos sobre la dinámica de la pobreza. Un punto particularmente crucial tiene que ver con la manera en que se ha definido la pobreza crónica y transitoria en donde coexisten dos tipos de enfoques. En el primero, el más utilizado (y el que hemos adoptado) es el hecho de cruzar la línea de pobreza, en un sentido u otro, lo que permite definir los estados de pobreza. En el segundo enfoque, en lugar de distinguir los individuos o los hogares en situación de pobreza crónica y transitoria, busca aislar un componente permanente y un componente transitorio de los ingresos de cada individuo u hogar (4). Tal aproximación es la propuesta hecha inicialmente por Ravallion (1988) en un artículo sobre la medición del riesgo y luego aplicada a las transiciones de pobreza por Jalan y Ravallion en sus estudios llevados a cabo sobre el sur de China (Jalan \& Ravallion, 1998; 2000). Este enfoque fue posteriormente también adoptado por McCulloch y Baulch en su estudio sobre hogares rurales de Pakistán (McCulloch \& Baulch, 1998; 1999). Ambas maneras de definir la pobreza permanente y transitoria, como ha señalado Yaqub, no son equivalentes. Así, en el caso de los hogares hindúes, estudiado por Gaiha \& Deolalikar (1993), sólo un tercio de los hogares con ingreso permanente por debajo de la línea de pobreza tenían ingresos corrientes que aparecían en cada uno de los nueve períodos cubiertos por la encuesta por debajo de la línea de pobreza (Yaqub, 2000a: 4). En fin de cuentas, la extrema heterogeneidad en los datos recogidos y en las metodologías hacen muy difícil la comparación de los resultados y ha hecho difícil investigar la existencia de regularidades y saber si las políticas de lucha contra la pobreza debían o no ser diferenciadas de acuerdo al carácter permanente o transitorio de la pobreza.

Cuadro 9 - Estudios en panel sobre la dinámica de la pobreza y de los ingresos.

\begin{tabular}{|llccccc|}
\hline \multicolumn{1}{|c}{ Fuente } & $\begin{array}{l}\text { País es- } \\
\text { tudiado }\end{array}$ & $\begin{array}{c}\text { Nro de } \\
\text { olas }\end{array}$ & $\begin{array}{c}\text { Pdo es- } \\
\text { tudiado }\end{array}$ & $\begin{array}{c}\text { Indic. de } \\
\text { bienestar }\end{array}$ & $\begin{array}{c}\text { Tamaño de } \\
\text { la muestra } \\
\text { panel }\end{array}$ & $\begin{array}{c}\text { Tema } \\
\text { estudiado }\end{array}$ \\
\hline $\begin{array}{l}\text { Reardon \& } \\
\text { Taylor (1996) }\end{array}$ & Burkina & 2 & $1983 / 84-$ & ingresos & 150 hogares & $\begin{array}{l}\text { Impacto de los } \\
\text { shocks climáticos } \\
\text { sobre la dinámica } \\
\text { de la pobreza. }\end{array}$ \\
\hline
\end{tabular}

(4) Se define la pobreza permanente como la distancia entre la línea de pobreza y el ingreso promedio a lo largo del período observado, mientras que la pobreza transitoria es el residuo entre la pobreza total y la pobreza permanente. 


\begin{tabular}{|c|c|c|c|c|c|c|}
\hline Carter (1999a) & $\begin{array}{l}\text { África del } \\
\text { Sur }\end{array}$ & 2 & $1993-98$ & gastos & 1183 hogares & $\begin{array}{l}\text { Dinámica de la } \\
\text { pobreza, movilidad } \\
\text { económica, papel } \\
\text { de los activos }\end{array}$ \\
\hline Carter (1999b) & $\begin{array}{l}\text { África del } \\
\text { Sur }\end{array}$ & 2 & $1993-98$ & gastos & 1183 hogares & $\begin{array}{l}\text { Dinámica de la } \\
\text { pobreza }\end{array}$ \\
\hline $\begin{array}{l}\text { Maluccio et al. } \\
\text { (2000) }\end{array}$ & $\begin{array}{l}\text { África del } \\
\text { Sur }\end{array}$ & 2 & $1993-98$ & gastos & 1400 hogares & $\begin{array}{l}\text { Dinámica social de } \\
\text { la pobreza }\end{array}$ \\
\hline $\begin{array}{l}\text { Dearcon \& } \\
\text { Krishnan (2000) }\end{array}$ & Etiopía & 3 & $1994-95$ & gastos & 1450 hogares & $\begin{array}{l}\text { Dinámica de la } \\
\text { pobreza y nutrición }\end{array}$ \\
\hline Gaiha (1989) & India & 3 & $\begin{array}{l}1968 / 69- \\
1970 / 71\end{array}$ & ingresos & 4118 hogares & $\begin{array}{l}\text { Características de } \\
\text { los pobres crónicos }\end{array}$ \\
\hline Gaiha (1988) & India & 3 & $\begin{array}{l}1968 / 69- \\
1970 / 71\end{array}$ & ingresos & 4118 hogares & $\begin{array}{l}\text { Transiciones de } \\
\text { pobreza y mov. } \\
\text { económica }\end{array}$ \\
\hline $\begin{array}{l}\text { Gaiha \& Deo- } \\
\text { lalikar (1993) }\end{array}$ & India & 9 & $\begin{array}{l}1975 / 76 \\
-1983 / 84\end{array}$ & ingresos & 170 hogares & $\begin{array}{l}\text { Pobreza crónica } \\
\text { según diferentes } \\
\text { enfoques }\end{array}$ \\
\hline $\begin{array}{l}\text { Chaudhri \& } \\
\text { Ravallion (1994) }\end{array}$ & India & 8 & $\begin{array}{l}1975 / 76 \\
-1982 / 83\end{array}$ & $\begin{array}{l}\text { ingresos, } \\
\text { gastos }\end{array}$ & 170 hogares & $\begin{array}{l}\text { Aspectos metodo- } \\
\text { lógicos de la focali- } \\
\text { zación de las políti- } \\
\text { cas sobre los } \\
\text { pobres crónicos }\end{array}$ \\
\hline $\begin{array}{l}\text { Lanjouw \& } \\
\text { Stern (1991) }\end{array}$ & India & 4 & $\begin{array}{l}1957 / 58- \\
1983 / 84\end{array}$ & ingresos & 143 hogares & $\begin{array}{l}\text { Transiciones } \\
\text { de pobreza }\end{array}$ \\
\hline $\begin{array}{l}\text { Walker \& Ryan } \\
\text { (1990) }\end{array}$ & India & 10 & $\begin{array}{l}1975 / 76 \\
-1984-85\end{array}$ & gastos & 240 hogares & $\begin{array}{l}\text { Dinámica socio- } \\
\text { económica }\end{array}$ \\
\hline $\begin{array}{l}\text { Grootaert \& } \\
\text { Kanbur (1995) }\end{array}$ & $\begin{array}{l}\text { Costa de } \\
\text { Marfil }\end{array}$ & 2 & $1985-86$ & gastos & 700 hogares & $\begin{array}{l}\text { Transiciones } \\
\text { de pobreza }\end{array}$ \\
\hline $\begin{array}{l}\text { Grootaert et al. } \\
\text { (1997) }\end{array}$ & $\begin{array}{l}\text { Costa de } \\
\text { Marfil }\end{array}$ & 2 & $1987-88$ & gastos & 700 hogares & $\begin{array}{l}\text { Determinantes de } \\
\text { las variaciones de } \\
\text { los gastos per cápita }\end{array}$ \\
\hline Herrera (1999) & Perú & 4 & $\begin{array}{l}1985,1990 \\
1994,1996\end{array}$ & gastos & 460 hogares & $\begin{array}{l}\text { Determinantes de las } \\
\text { transiciones de po- } \\
\text { breza, movilidad } \\
\text { económica }\end{array}$ \\
\hline Herrera (2001a) & Perú & 3 & 1997- 1999 & gastos & 3100 hogares & $\begin{array}{l}\text { Determinantes de las } \\
\text { transiciones de } \\
\text { pobreza }\end{array}$ \\
\hline $\begin{array}{l}\text { Cumpa \& Webb } \\
\text { (1999) }\end{array}$ & Perú & 3 & $\begin{array}{l}\text { 1991, 1994, } \\
1996\end{array}$ & gastos & 676 hogares & $\begin{array}{l}\text { Transiciones } \\
\text { de pobreza }\end{array}$ \\
\hline $\begin{array}{l}\text { Glewwe \& } \\
\text { Hall (1995) }\end{array}$ & Perú & 2 & $\begin{array}{l}1985 / 86 \\
-1990\end{array}$ & gastos & 699 hogares & $\begin{array}{l}\text { Determinantes de } \\
\text { las variaciones de } \\
\text { los gastos per cápita }\end{array}$ \\
\hline Jalan \& & China & 6 & $1985-90$ & gastos & 38000 & Pobreza transitoria \\
\hline
\end{tabular}




\begin{tabular}{|c|c|c|c|c|c|c|}
\hline Ravallion (1998) & & & & & individuos & $\begin{array}{l}\text { y crónica, focaliza- } \\
\text { ción de los pobres }\end{array}$ \\
\hline $\begin{array}{l}\text { Jalan \& } \\
\text { Ravallion (2000) }\end{array}$ & China & 6 & $1985-90$ & gastos & $\begin{array}{l}38000 \\
\text { individuos }\end{array}$ & $\begin{array}{l}\text { Determinantes de } \\
\text { la pobreza transi- } \\
\text { toria y crónica }\end{array}$ \\
\hline $\begin{array}{l}\text { McCulloch \& } \\
\text { Calandrino } \\
\text { (2002) }\end{array}$ & China & 5 & $1991-95$ & ingresos & 3311 hogares & $\begin{array}{l}\text { Dinámica de } \\
\text { la pobreza, } \\
\text { vulnerabilidad }\end{array}$ \\
\hline $\begin{array}{l}\text { McCulloch \& } \\
\text { Baulch (1998) }\end{array}$ & Pakistán & & $\begin{array}{l}1986 / 87- \\
1990 / 91\end{array}$ & ingresos & 686 hogares & $\begin{array}{l}\text { Transiciones } \\
\text { de pobreza }\end{array}$ \\
\hline $\begin{array}{l}\text { McCulloch \& } \\
\text { Baulch (1999) }\end{array}$ & Pakistán & 5 & $\begin{array}{l}1986 / 87 \\
-1990 / 91\end{array}$ & ingresos & 686 hogares & $\begin{array}{l}\text { Determinantes } \\
\text { de la pobreza tran- } \\
\text { sitoria y crónica }\end{array}$ \\
\hline $\begin{array}{l}\text { Mroz \& Popkin } \\
\text { (1995) }\end{array}$ & Rusia & 4 & 1992-94 & ingresos & $\begin{array}{l}6300 \\
\text { viviendas }\end{array}$ & $\begin{array}{l}\text { Transiciones de po- } \\
\text { breza y de empleo }\end{array}$ \\
\hline $\begin{array}{l}\text { Scott \& Litch- } \\
\text { field (1994) }\end{array}$ & Chile & 2 & $\begin{array}{l}1967 / 69 \\
-1985 / 86\end{array}$ & ingresos & 146 hogares & $\begin{array}{l}\text { Determinantes de } \\
\text { la movilidad } \\
\text { económica y la } \\
\text { desigualdad }\end{array}$ \\
\hline Scott (2000) & Chili & 2 & $\begin{array}{l}1967 / 69 \\
-1985 / 86\end{array}$ & ingresos & 146 hogares & $\begin{array}{l}\text { Transiciones de } \\
\text { pobreza }\end{array}$ \\
\hline $\begin{array}{l}\text { Glewwe } \text { et al. } \\
(2000)\end{array}$ & Vietnam & 2 & $\begin{array}{l}\text { 1992-93, } \\
1997-98\end{array}$ & gastos & 4281 hogares & $\begin{array}{l}\text { Determinantes de } \\
\text { la pobreza transi- } \\
\text { toria y permanente }\end{array}$ \\
\hline Freire (2000) & Venezuela & 2 & $1997-98$ & ingresos & 7744 hogares & $\begin{array}{l}\text { Movilidad econó- } \\
\text { mica y transicio- } \\
\text { nes de pobreza }\end{array}$ \\
\hline
\end{tabular}

Fuentes: elaboración propia, Yaqub (2000a); Baulch \& Hoddinnt (2000: 7).

El enfoque que aquí se propone constituye, hasta donde sabemos, el primer estudio comparativo que versa no solamente sobre la importancia de las transiciones de pobreza, sino también sobre los determinantes de la dinámica de la pobreza en dos países en desarrollo. Esta comparabilidad ha sido asegurada por un método idéntico en la construcción de los indicadores de bienestar, en la definición de línea de pobreza, en la consideración del mismo tipo de hogares (urbanos), por un número igual de olas de panel, por el período en estudio (1997-1999), por la definición rigurosamente idéntica de las variables explicativas, y, en fin, por la formulación y estimación del modelo explicativo por el mismo método econométrico. Nuestro estudio se diferencia también de otros porque ha considerado, además de las habituales características socioeconómicas individuales de los jefes de familia y de las características de los hogares a los que pertenecen, los shocks no contemporáneos sufridos por estos hogares (shocks del mercado de trabajo, shocks demográficos) (5). Finalmente se diferencia de

(5) Evitando así el problema del sesgo de simultaneidad presente en ciertos estudios en los que el panel se despliega únicamente sobre dos períodos en lugar de tres, como el caso estudiado aquí (ver Glewwe et al., 2000, sobre este punto). 
los presentados en la revisión de la literatura por tomar en cuenta variables relacionadas con la localización espacial de los hogares.

\section{2. El modelo econométrico}

En la sección anterior, que ha versado sobre el perfil de las transiciones de pobreza, se ha examinado de algún modo los riesgos incondicionales que corren los hogares con diferentes características de hallarse en uno de los estados de transiciones de pobreza. Ello ha permitido identificar qué variables son potencialmente pertinentes para la política de lucha contra la pobreza crónica y la pobreza transitoria. Una aproximación más analítica requiere aislar el efecto específico de cada variable manteniendo ahora constante el impacto de las demás variables. Esta sección está consagrada a la modelización de los factores asociados con las entradas y salidas de la situación de pobreza así como con las condiciones de "pobres crónicos" y los "jamás pobres".

Hemos optado por modelizar las transiciones de pobreza en lugar de modelizar la dinámica de los ingresos (6). Se pondrá atención, por tanto, sobre las variaciones discretas de los ingresos por debajo y por encima de la línea de pobreza. La variable dependiente corresponde a los cuatro estados de transición de pobreza (pobreza crónica (7), salida de pobreza, entrada en pobreza y no pobreza) observados entre 1998 y 1999. El modelo estimado es de tipo logit multinomial, de suerte que una misma variable puede tener un impacto diferente según el tipo de transición de pobreza:

$$
\begin{aligned}
& \mathrm{P}_{\mathrm{ij}}\left(\mathrm{y}_{\mathrm{i}}=1 \mid \mathrm{x}_{\mathrm{i}}\right)=1 / \sum_{\mathrm{j}=2}^{4} \mathrm{e}^{\mathrm{b}(\mathrm{j}) \mathrm{Xi}} \\
& \mathrm{P}_{\mathrm{ij}}\left(\mathrm{y}_{\mathrm{i}}=\mathrm{m} \mid \mathrm{x}_{\mathrm{i}}\right)=\mathrm{e}^{\mathrm{b}(\mathrm{j}) \mathrm{Xi}} / \sum_{\mathrm{j}=2}^{4} 1+\mathrm{e}^{\mathrm{b}(\mathrm{j}) \mathrm{Xi}} \quad \text { para } 4>\mathrm{m}>1
\end{aligned}
$$
pobreza j.

Donde Prij es la probabilidad de que el hogar i se halle en la transición de

Se han considerado cuatro conjuntos de variables: tres de ellas se refieren a las características del jefe de hogar, características del hogar y características del barrio; mientras que el último corresponde a shocks sufridos por los hogares, los mismos que han sido subdivididos en varios subconjuntos: los shocks demográficos y los shocks económicos. Para evitar los problemas de simultaneidad y endogeneidad ya mencionados, las variables estructurales son las del inicio de período (1998) y los shocks se refieren al período anterior a las transiciones (1997-1998), aprovechándose así los tres puntos en el tiempo que disponemos. Las variables han sido consideradas bloque por bloque, lo que permite evaluar la robustez de los resultados. La selección del tipo de modelización hacen necesario un cierto número de comentarios.

(6) Tal es la aproximación adoptada por Glewwe \& Hall (1995) y por Grootaert \& Kanbur (1995). En una versión ulterior de este trabajo se incluirá una modelización de las variaciones de los ingresos.

(7) El término de "pobreza crónica" ha sido preferido al de "pobreza permanente" en razón del breve período de observación del cual se dispone (2 años). 
En primer lugar, la consideración de cuatros estados de pobreza y en particular la distinción al interior de la pobreza transitoria entre las entradas y salidas de pobreza se justifica por dos series de razones ligadas entre ellas. Desde el punto de vista económico, los factores susceptibles de hacer caer a un hogar en la pobreza no son necesariamente los mismos (en el sentido opuesto) que aquellos que están asociados a las salidas de pobreza, en cuyo caso las políticas de lucha contra la pobreza no serían necesariamente las mismas. Bastaría considerar la posibilidad de existencia de trampas de pobreza para explicar tal asimetría. Desde el punto de vista estadístico, la hipótesis de la existencia de cuatro estados diferenciados de pobreza es confirmada dado que los tests de Wald han rechazado la hipótesis que los cuatros estados podían ser agregados, de suerte que las variables explicativas consideradas permiten diferenciar entre los diferentes estados de pobreza analizados.

En segundo lugar, dado que el estatus de transición de pobreza está completamente determinado por la posición relativa de los ingresos respecto a la línea de pobreza, un modelo de determinación de ingresos en panel hubiera podido ser considerado como más pertinente, desde la perspectiva de maximizar la información disponible (particularmente los montos de los ingresos). En un primer tiempo, dos razones nos han conducido a descartar esta solución aunque no descartamos esta pista en una futura investigación. Primeramente, siendo nuestro objetivo el poder comparar nuestros resultados con los obtenidos por los autores citados previamente, es conveniente adoptar una estrategia de modelización similar. Enseguida, ingresos y pobreza son tanto menos equivalentes en la medida que hemos adoptado una línea de pobreza absoluta cuya definición es próxima del umbral fisiológico. Podemos por ende pensar que atravesar la línea de pobreza tiene un sentido económico y consecuencias específicas para los hogares afectados, lo cual no sería el caso si hubiéramos considerado una línea de pobreza relativa. Además, el efecto de las variables explicativas sobre los ingresos no es necesariamente linear y puede por ende ser diferente por encima y por debajo de la línea de pobreza. Finalmente, la agregación de los ingresos en dos categorías (pobres/no pobres) permite limitar el impacto del sesgo causado por los errores en la medición de los ingresos que sabemos no son despreciables. En contrapartida, conviene cerciorarse que los cambios de estatus de pobreza no son producto de pequeñas variaciones de los ingresos de un período a otro, las cuales podrían ser imputables a los errores de medición. Está posibilidad puede ser globalmente rechazada en el caso de los dos países bajo estudio. En efecto, las variaciones en los ingresos de los hogares que entran o que salen de la pobreza son bastante significativas, manteniéndose sin embargo dentro de una amplitud "razonable" incluso a corto plazo y perfectamente compatibles con los shocks exógenos (macroeconómicos y climáticos) que sufren los hogares en los países en desarrollo ante la ausencia de protección social institucionalizada (ver anexo). Así, tanto en Madagascar como en el Perú, cerca del $85 \%$ de los ingresos o de las salidas de la pobreza entre 1998 y 1999 han sido suscitados por variaciones de más del $30 \%$ de los ingresos (8).

(8) Ver McCulloch \& Baulch (1998) para un argumento similar. Se encontró un resultado semejante en el caso de Francia, por Maurin y Chambaz, lo cual indujo a los autores a plantear la hipótesis de que las transiciones eran reflejo de discontinuidades en la vida profesional y/o familiar de los hogares, es decir en la "manera misma en que se forman los ingresos" (Maurin \& Chambaz, 1996: 140). 
Finalmente, el tema de los shocks requiere ser desarrollado un poco más. La hipótesis subyacente de las investigaciones citadas anteriormente, y que intentaremos someter a prueba, es que la escasa dotación de activos físicos y en capital humano está asociada principalmente con la pobreza crónica, mientras que la pobreza transitoria se encuentra más vinculada con los diferentes shocks sufridos por los hogares y que acarrean una mayor variabilidad de los ingresos. Tales shocks pueden ser de diferente naturaleza. Jenkins (1998), siguiendo el trabajo de Bane \& Ellwood (1986) ha propuesto una jerarquía de acontecimientos relacionados con las transiciones de pobreza. El autor sugiere examinar primero si ha habido o no cambio de jefe de hogar. Si tal es el caso, conviene precisar qué tipo de cambio demográfico está relacionado con la transición de pobreza examinada. Entre los sucesos demográficos se pueden citar la llegada de nuevos miembros, ya sea por nacimiento, matrimonio, llegada de otros parientes o de no parientes, o bien la disminución del tamaño del hogar por el deceso de un miembro, la ruptura de la pareja, hijos que abandonan el hogar y otros parientes y no parientes que también lo dejan. En cuanto a los hogares que conservan el mismo jefe, Jenkins sugiere comparar la evolución de las necesidades respecto a la evolución de los ingresos monetarios, precisando cuál ha sido la fuente que más ha contribuido. Entre los sucesos vinculados con la evolución de los ingresos se pueden citar las variaciones de los ingresos del jefe de hogar; los del cónyuge, las variaciones de los ingresos procedentes del trabajo, y otros ingresos diferentes de los del trabajo (transferencias, ingresos del capital, etc.) (Jenkins, 1998: 34).

Se trata, pues, de identificar y precisar el papel de las principales variables que explican las transiciones de pobreza. Ya que el indicador de bienestar es el ingreso familiar per cápita, las transiciones dependen directamente de las variaciones del ingresos de los miembros del hogar y de la composición demográfica del mismo. Las variaciones del ingreso pueden sobrevenir a través de los sucesos vinculados con la formación de los ingresos (la dotación de activos del hogar - activos físicos, capital humano y capital social- y el rendimiento de los activos), así como a través de los cambios en la composición de los hogares (que afectan tanto al numerador como al denominador del ingreso per cápita), o a los dos al mismo tiempo. Los sucesos o shocks pueden afectar de manera individual el hogar (shock idiosincrático) o a un conjunto de hogares (Jenkins, 1999: 4-5; Baulch \& Hoddinnot, 2000: 11) (9). Hay que subrayar

(9) Bane \& Ellwood (1986) en su estudio sobre los hogares americanos han subrayado la importancia de sucesos o de shocks demográficos en las transiciones de pobreza. Así, constatan que menos del $60 \%$ de las entradas en la pobreza han sido desencadenadas por un descenso de los ingresos del jefe de hogar, mientras que $60 \%$ de las salidas de la pobreza son consecutivas al aumento de los ingresos del jefe de hogar. Los autores citados recomiendan por lo tanto focalizar las investigaciones en las decisiones de formación de hogares y el comportamiento de los miembros secundarios del hogar (Bane \& Ellwood, 1986: 1). En cambio, en el caso del Reino Unido, Jenkins encuentra que el comportamiento de los miembros secundarios del hogar prevalece sobre los cambios demográficos en las explicaciones de las transiciones de pobreza: $82 \%$ de las salidas de pobreza se hallaban vinculadas con acontecimientos favorables en lo que respecta a los ingresos, y solamente el $18 \%$ de los cambios demográficos. La importancia de los cambios demográficos es superior en el caso de las entradas en pobreza (38\% de los casos) (Jenkins 1998: 12-13). En el caso de Madagascar y el Perú, donde la tasa de participación del cónyuge es más baja que en los países desarrollados mostraría tendencia a acentuar el efecto demográfico mientras que la mayor frecuencia de hogares ampliados tendería más bien a contrarrestar tal efecto. 
que, al sólo disponerse de un breve período de observación, no es posible considerar los shocks de tipo macroeconómico (crecimiento, inflación, etc.) o que afectan el entorno del mercado de trabajo (liberalización, salario mínimo, etc.).

El tratamiento econométrico de los shocks plantea un arduo problema de arbitraje. Para evitar el sesgo de simultaneidad, es necesario descartar los shocks contemporáneos y sólo considerar los shocks pasados. Sin embargo, en contrapartida se pierde toda la información, ya conocida, sobre los shocks contemporáneos. Ahora bien, resulta claro que, por ejemplo, un shock adverso (jefe que deja el hogar, pérdida del empleo, etc.) entre $t-1$ y $t$ tendrá un mayor impacto sobre los ingresos en $t$ respecto a shocks ocurridos entre $t-2$ y $t-1$ (que es lo que corresponde a nuestra modelización). Dado que nos interesamos a las transiciones de pobreza ocurridas entre $\mathrm{t}-1 \mathrm{y} \mathrm{t}$, la naturaleza de los datos no permiten conocer el orden en el cual los eventos han ocurrido, no es posible por ello afirmar que el shock ocurrió antes de la transición de pobreza y no a la inversa.

\section{Recuadro - Lectura de los resultados}

La lectura e interpretación de los resultados de un modelo logit multinomial es ardua por el número de estados (la variable dependiente tiene en nuestro caso cuatro modalidades) y de variables explicativas, con el añadido aquí de la comparación entre los dos países. Así, por ejemplo, la probabilidad que y=2 (entrada en pobreza) relativa a la modalidad de referencia ( $\mathrm{Y}=4$ pobres crónicos) (riesgo relativo) para una variación unitaria de $\mathrm{Xi}$ esta dada por:

$\operatorname{Pij}(y i=2 \mid x i)=e b i(2)$

Pij (yi $=4 \mid x i)$

Sin embargo, una variable puede ser significativa para explicar la probabilidad relativa de una modalidad en relación con la modalidad de referencia escogida (pobreza permanente en nuestros cuadros), y sin embargo no ser significativa en relación con otra modalidad de referencia. A fin de facilitar la lectura e interpretación de los principales resultados, un cierto número de opciones han sido adoptadas:

A pesar de que las regresiones hayan sido estimadas a partir de un modelo multinomial con cuatro modalidades, los comentarios de resultados se refieren a la pareja de resultados para quienes el contraste nos parece más "natural". En primer lugar, la pobreza crónica es confrontada con la situación de nunca pobres, ambos estados corresponden a los dos casos extremos. Enseguida, en el análisis de las transiciones, el estado de referencia de pobreza escogido es aquel que comparte el mismo punto de partida: salidas de la pobreza versus pobreza crónica y entradas en pobreza versus nunca pobres. Para este efecto, las estimaciones han sido efectuadas cambiando las modalidades que sirven de referencia.

- Los coeficientes por analizar serán expresados en términos de "odds ratios" (riesgos relativos), los cuales son simplemente el exponencial del coeficiente de regresión $\left(\mathrm{e}^{\mathrm{b}}\right)$. Un coeficiente superior a 1 indica que la variable en referencia aumenta la probabilidad, por ejemplo, de salir de la pobreza en relación con la 
situación de pobreza permanente. Inversamente, un coeficiente inferior a 1 indica que la variable examinada tiene un impacto negativo sobre la probabilidad relativa de una transición en relación con el caso de base. Los "odds ratio" tienen la ventaja, a diferencia de los efectos marginales, de no depender de los valores de las restantes variables, además de la variable concernida.

- Utilizaremos de manera complementaria del método gráfico desarrollado por Long \& Freese (2001). Estos gráficos son presentados en el anexo, y corresponden a la estimación del modelo que considera el conjunto de las variables (regresión $\mathrm{N}^{\circ} 1$ ). Este método permite observar los efectos de cada variable explicativa sobre las diferentes modalidades de la variable dependiente (las diferentes transiciones de pobreza). Los "odd ratios" de cada uno de los cuatro estados de transiciones de pobreza, a saber los pobres permanentes $(\mathrm{P})$, los jamás pobres $(\mathrm{J})$, los que ingresan en pobreza $(\mathrm{E})$ y los que salen de ella $(\mathrm{S})$, pueden ser leídos por la distancia que separa dos puntos que representan las transiciones de pobreza. Si estos dos puntos son unidos mediante una raya, entonces el "odds ratio" no es estadísticamente significativo, de modo que la variable afectada no permite diferenciar los dos estados.

\section{3. Resultados de las estimaciones}

Para comentar los resultados de nuestros modelos de transiciones de pobreza adoptaremos el siguiente plan. Comenzaremos por una comparación de ambos estados extremos: pobreza crónica y situación de no pobreza, para centrarnos luego en los factores más particularmente asociados con las salidas y entradas en pobreza. Evidentemente este segundo aspecto es el que presenta mayor interés. En efecto, los factores asociados con las salidas de pobreza, así como los vinculados con las entradas en pobreza han sido muy poco estudiados en los países en desarrollo. El objetivo central del presente estudio es, pues, apreciar si las formas transitorias de pobreza que como hemos visto corresponden a dos poblaciones de características propias, responden a causas diferentes, y deben por lo tanto necesitar políticas diferenciadas para combatirlas. En cada uno de los casos se analizará en primer lugar los determinantes comunes a ambos países, mientras que las diferencias serán detalladas luego.

\section{3. 1. Pobreza crónica versus no pobreza}

Los factores de riesgo de pobreza permanente en relación con la no pobreza son ya clásicos y recubren en gran parte las variables tradicionales de las ecuaciones de pobreza estática. Son además comunes a ambos países. Así, un gran tamaño del hogar y una más alta proporción de niños pequeños aumentan las probabilidades de pobreza crónica. Sin embargo, este resultado debe interpretarse con prudencia debido a que no se ha efectuado ninguna corrección a fin de tener en cuenta las escalas de equivalencia ni las economías de escala.

La dotación del capital humano (inversión escolar) y física (elementos del patrimonio) del hogar actúan, igualmente, en favor de la protección contra la pobreza 
crónica. El efecto positivo de la educación, ya bastante pronunciado, es siete veces superior en Madagascar que en el Perú. Además, sus perfiles son diferentes. En el gráfico $\mathrm{n}^{\circ} 4$ se muestra cómo varía la probabilidad relativa de ser "nunca pobre" respecto a ser "pobre crónico", en función de la dotación de capital humano del hogar (10), manteniendo constante las otras variables en sus niveles promedio. En Madagascar, el "rendimiento" de la educación sobre la probabilidad de ser "nunca pobre" est fuertemente creciente mientras que en el Perú es ligeramente decreciente y tiene una pendiente bastante menos pronunciada (el impacto potencial se mantiene confinado en un rango más estrecho, de alrededor de 0,6 a 0,85 ). Esto significa que las estrategias "familiares" de acumulación de capital humano (escolarización de los hijos, continuación de estudios secundarios, incluso universitarios) tienen un "rendimiento" diferencial muy importante en Madagascar en relación con el Perú.

Una inserción de calidad en el mercado de trabajo, en particular en tanto que asalariado del sector público, empleado o fuera del sector primario, limita los riesgos de pobreza crónica. Entonces, a pesar de la fuerte tendencia a la precariedad del empleo asalariado y la caída de los salarios de los funcionarios, estos empleos se sitúan en lo alto de la jerarquía profesional. En ninguno de los dos países el recurso a la ocupación secundaria permite escapar a la pobreza. Al hallarse dotado ya de un bajo capital humano, y teniendo que trabajar por cuenta propia, para la mayoría el margen para ocupar un segundo empleo remunerador que permita escapar a la pobreza permanente resulta, pues, muy reducido. En fin, tanto en el Perú como en Madagascar, el no acceso a los bienes públicos, como la electricidad es una "marca" significativa del estatus de pobreza crónica. La fuerte expansión geográfica en la periferia de las grandes ciudades, en lo que se ha convenido en llamar "asentamientos humanos" con viviendas precarias, explica por qué en el Perú (y no en Antananarivo) la falta de servicios higiénicos en el interior de la vivienda está asociado también con la pobreza crónica.

De manera más original, el nivel de riqueza del barrio de residencia (ingreso promedio del barrio) también tiene un impacto sobre las probabilidades de escapar a la pobreza, una vez considerado el efecto de las demás variables explicativas. Una buena localización geográfica es, pues, susceptible de crear externalidades positivas: a características observables idénticas, los hogares que viven en barrios favorecidos se benefician de un entorno favorable (acceso a los servicios públicos colectivos, capital social, sobre todo demanda superior para los informales, etc.), para aprovechar más fácilmente las oportunidades del mercado, lo cual les permite generar ingresos superiores. Ninguna de las variables de shocks es significativa, conformemente al modelo estructural que hemos presentado más arriba.

En cambio, ciertas variables no afectan de la misma manera a los dos países. Por ejemplo, el sexo del jefe de hogar no tiene ninguna influencia específica sobre el estatus de pobreza en el Perú, mientras que las mujeres jefes de hogar parecen desfavorecidas en Madagascar a pesar de una situación escolar más equitativa en este país. Los hogares jefaturados por hombres tienen probabilidades casi tres veces

(10) El indicador de capital humano del hogar es el promedio para el conjunto de miembros del coeficiente: número de años de estudios aprobados sobre el número de años de estudios teóricos posibles, los cuales dependen de la edad de cada miembro. Este indicador varia entre 0 y 1. 

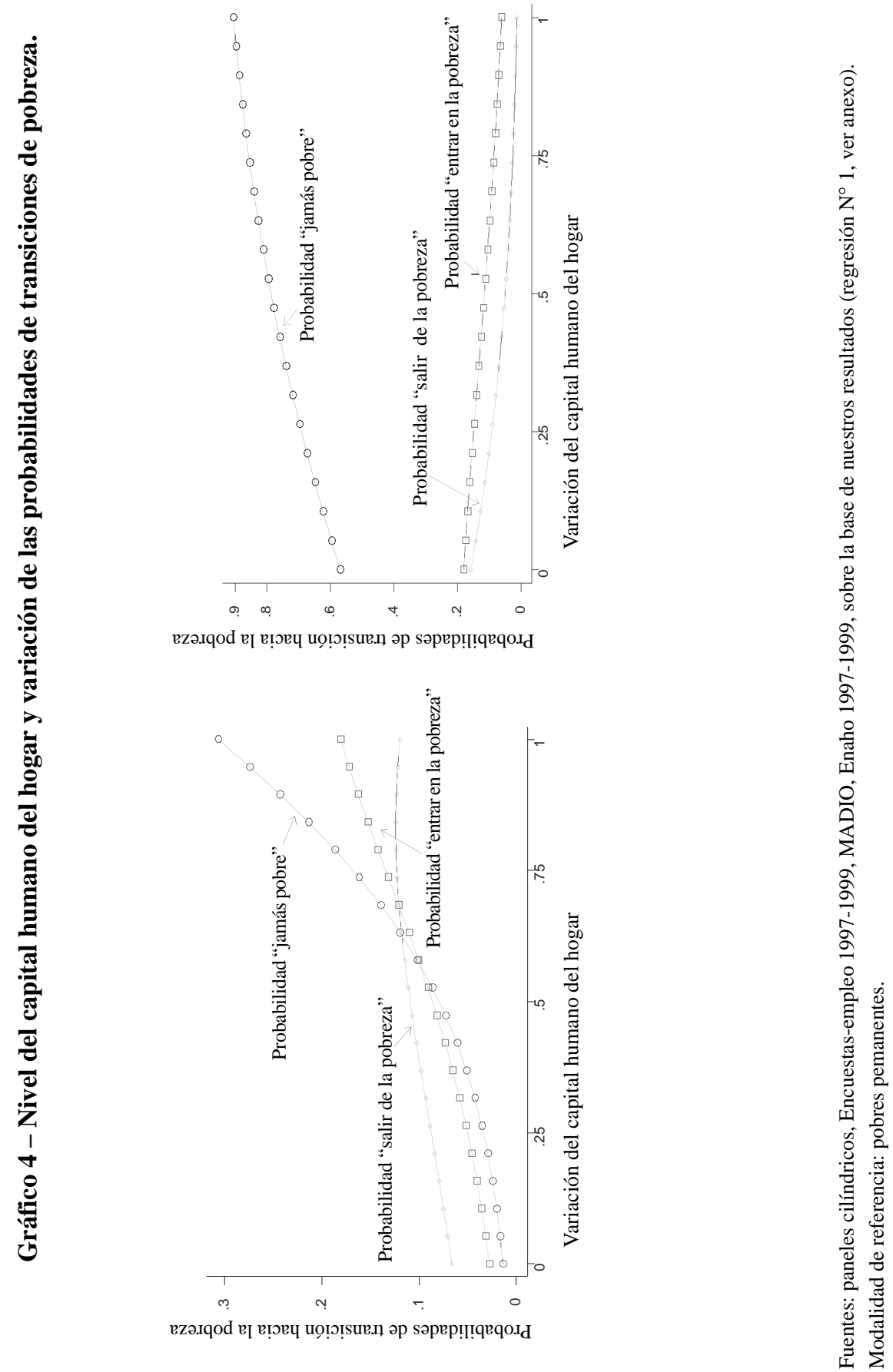
superiores a los jefes de sexo femenino de ser no pobres en relación con la situación de pobre crónico. En el Perú, donde las mujeres jefes de hogar pertenecen a menudo a organizaciones barriales ("comedores populares") se observa el resultado inverso, sin que sea significativo desde el punto de vista estadístico. Dado que hemos controlado el efecto de la composición demográfica de los hogares así como el capital humano y el tipo de inserción profesional, podríamos postular que las mujeres malgaches sufren discriminaciones de ingresos más importantes que sus homólogas peruanas. En el mismo orden de ideas, los hogares conformados por parejas en unión libre se halla estigmatizados y desfavorecidos en Madagascar mas no en el Perú. El peso de un rigorismo religioso más enraizado en el primer país.

Otro resultado contrastado y a priori contra-intuitivo es que la proporción de trabajadores informales en el barrio de residencia contribuye a disminuir sensiblemente los riesgos de pobreza crónica en la capital malgache. Inversamente, en el Perú esta variable tiene el impacto negativo esperado, aunque no significativo desde el punto de vista estadístico. Este resultado podría ser el signo de una mayor integración de los informales en Madagascar; la densidad de la informalidad en el barrio estaría ligada a la importancia de redes de solidaridad y al capital social. En efecto, en Madagascar una proporción más importante de informales trabaja en su domicilio, utiliza la mano de obra familiar y realiza sus ventas en el barrio de residencia, a la diferencia de sus homólogos peruanos que residen principalmente en barrios periféricos relativamente recientes y alejados de los lugares de ventas situados en los barrios comerciales del centro consolidado de la ciudad.

\section{3. 2. Entradas y salidas de la pobreza}

Hemos visto que la pobreza crónica podía ser distinguida de las formas transitorias de la pobreza. Queda por identificarse los factores específicos ligados a las entradas y salidas de la pobreza y en particular el papel de los shocks sufridos por los hogares. A fin de facilitar la comprensión de los resultados, la situación de no pobreza servirá de término de referencia para establecer los contrastes con las entradas en pobreza, mientras que la situación de pobreza crónica será utilizada como situación de referencia para las salidas de pobreza. Antes de comentar nuestros resultados, conviene anotar que las variables que representan los shocks sufridos por los hogares se refieren al período 1997/1998, mientras que las transiciones de pobreza que se trata de explicar corresponden al período 1998/1999. Nuestra aproximación se diferencia de la de Freire para el caso de Venezuela, donde los shocks son simultáneos con las transiciones de una panel de sólo dos olas (Freire, 2000), de manera que se evita un posible sesgo de simultaneidad en nuestras estimaciones (11). Más aún, al considerar los shocks simultáneos con las transiciones obtenemos artificialmente en el caso de Madagascar una mejor calidad predictiva del modelo (el seudo $\mathrm{R}^{2}$ pasa de 0,35 a 0,38 ), mientras que en el caso del Perú el test de Wald para el conjunto de los coeficientes de shocks se hace significativo al $5 \%$.

(11) Este problema es abordado explícitamente por Glewwe et al. (2000). 
Los factores estructurales de las salidas de la pobreza son, en su conjunto, los mismos que aquellos que inciden sobre la pobreza crónica (tamaño y composición del hogar, capital humano y físico, inserción en el mercado de trabajo, acceso a las infraestructuras públicas). Globalmente y para cada país, los coeficientes de regresión tienen el mismo signo pero son más débiles y a menudo no son estadísticamente significativos. Las dificultades de los hogares jefaturados por mujeres en Madagascar se confirma pues tienen también mayores dificultades para salir de la pobreza. Las características espaciales actúan en el sentido esperado: la proporción de informales en el barrio inhibe las salidas de la pobreza en el Perú mientras que la concentración de capital humano los favorece en Madagascar.

Los shocks, por el contrario, juegan un papel más importante que en el caso de la pobreza crónica, contexto en el cual no tienen ningún impacto, en particular en el caso del Perú. En este país la pérdida del jefe del hogar disminuye las probabilidades de salir de la pobreza y lo contrario ocurre cuando el cónyuge se suma al hogar. Este resultado concuerda con los hallados por estudios similares en países desarrollados en donde los shocks demográficos revisten importancia en las transiciones de pobreza. Los shocks económicos vinculados al mercado de trabajo tienen importancia. El aumento de número de miembros activos en el hogar acrecienta también fuertemente las posibilidades de salida de la pobreza. Además, el sector institucional en el que los nuevos miembros activos se insertan reviste también importancia. En efecto, un incremento en el grado de "informalización" de la mano de obra familiar entraba las salidas de la pobreza.

Ahora se vuelve la atención hacia las entradas en pobreza, cuyos riesgos relativos serán analizados respecto a la situación de permanecer fuera de la pobreza entre 1998 y 1999. Se trata aquí de identificar los factores de vulnerabilidad que aumentan las probabilidades de caer en una situación de pobreza, cuando anteriormente el hogar se había librado de esa situación. Una primera idea bastante difundida es refutada por nuestros resultados. El hecho que el hogar sea jefaturado por una mujer no es en sí factor de vulnerabilidad en cuanto a las entradas en pobreza. Este resultado ha sido puesto también en evidencia en Venezuela tanto para las entradas como para las salidas de la pobreza (Freire, 2000: 25-26). O también en Vietnam, y ello tanto en las zonas urbanas como rurales (Glewwe et al., 2000: 34). En Polonia, Okrasa halló un resultado similar al constatar que los hogares dirigidos por una mujer tenían de hecho menos probabilidades de ser pobres o vulnerables (Okrasa, 1999: 24). Respecto a los dos países que analizamos, en Madagascar los hogares jefaturados por mujeres tienen un riesgo más elevado de encontrarse en situación de pobreza crónica respecto a los otros estados de pobreza, sin que puedan distinguirse entre sí bajo este criterio, mientras que en el Perú el género del jefe de hogar no tiene ningún impacto específico.

En cambio, el tamaño del hogar y la proporción de niños en el hogar en Madagascar constituyen factores de riesgo seguros de entrada en pobreza. La dotación en capital físico y humano permite limitar las entradas en pobreza. El ejercer un empleo en el sector primario en el Perú, o en tanto que trabajador con bajas calificaciones en Madagascar constituyen también factores de riesgo. A diferencia del caso peruano, donde era un factor que permitía la salida de la pobreza, la ocupación secundaria del 
jefe de hogar en Madagascar constituye un factor de riesgos de entrada en la pobreza. Cuanto más se acumulan empleos de mala calidad, mayores son los riesgo de entrar en pobreza. Las variables ligadas a la ubicación geográfica de los hogares no juegan ningún papel aparente sobre los riesgos de entradas en pobreza, con la excepción de la tasa de informalidad, que más bien reduce dichas probabilidades. Este resultado paradójico ya ha sido discutido más arriba a propósito de la pobreza crónica.

Pocas variables vinculadas con los cambios sufridos por los hogares resultan significativos en nuestras estimaciones econométricas. Entre estas se puede retener en el Perú el hecho de que la partida de otros miembros del hogar (que no hacen parte del hogar nuclear) disminuye el riesgo de ingresar en la pobreza, lo cual hace suponer que se trata de miembros que no contribuyen, o lo hacen en muy poca medida, a los ingresos del hogar. En Madagascar se nota curiosamente que el cambio de estatus de ocupación del jefe de hogar, más precisamente la pérdida del empleo, sea a causa de la desocupación o sea a causa de la salida a la inactividad, constituye un factor que reduce el riesgo de entrar en la pobreza. Ello de hecho refleja un sentido de causalidad invertida. Es cuando el hogar alcanza un nivel de ingresos suficiente que el jefe puede permitirse salir de la fuerza de trabajo o declararse desocupado. Algo más importante, el aumento en el hogar del número de informales, de asalariados del sector privado o de desocupados/inactivos (en relación con los asalariados del sector público) incrementa los riesgos de entrar en la pobreza.

Finalmente, todos los estudios empíricos sobre los determinantes de las transiciones de pobreza tienen en común la dificultad de identificar variables asociadas con formas transitorias de pobreza. Baulch y McCullogh identifican la tasa de dependencia como única variable que permite distinguir la pobreza permanente y la pobreza transitoria (McCullogh \& Baulch, 1999: 17). El modelo estimado para China meridional por Jalan y Ravalllion posee una mayor capacidad predictiva en el caso de la pobreza crónica que en el de la transitoria. Las variables más importantes que determinan la pobreza transitoria son las vinculadas con el ciclo de vida (edad y edad al cuadrado) y a los activos. Ni el nivel de educación ni las características demográficas del hogar (salvo la proporción de niños entre 6 y 14 años) parecen tener impacto sobre la pobreza transitoria. Estos mismos autores identifican las características demográficas (tamaño del hogar, niveles de educación, estructura demográfica) así como la variabilidad de los rendimientos agrícolas y la tasa de analfabetismo de la localidad como las variables que tienen mayor importancia para la pobreza permanente en relación con la pobreza transitoria. Los autores concluyen que los determinantes de la pobreza crónica, y los de la transitoria son muy diferentes (Jalan \& Ravaillon, 2000: 93-95). En el caso estudiado por Glewwe et al. (2000), ninguna variable explicativa ha resultado significativa para dar cuenta de las entradas en pobreza en un medio urbano, mientras que en un medio rural la categoría socioprofesional del jefe del hogar, su educación, el tamaño del hogar y su composición demográfica, los activos (tierra con riego), la productividad agrícola, el acceso a los mercados y bienes públicos (oficina de correos) tienen todos un impacto significativo sobre la probabilidad de entrar en la pobreza respecto a mantenenrse en situación de pobreza crónica (Glewwe et al., 2000: 53-54). 
El aspecto decepcionante de los modelos explicativos de la pobreza transitoria es su baja capacidad predictiva. Mientras que la capacidad predictiva del modelo es muy aceptable en el caso de los pobres permanentes y de los individuos jamás pobres, es muy insuficiente, incluso casi nula, en el caso de las entradas y salidas de la pobreza (12). En efecto, el modelo estimado (ver regresión $\mathrm{N}^{\mathrm{o}} 1$ en anexo) predice correctamente los casos de hogares jamás pobres en un $87 \%$ y $61 \%$ de casos para el Perú y Madagascar, respectivamente. Estas proporciones son de $41 \%$ y $89 \%$ en el caso de pobres permanentes para los mismos países. En cambio, menos de 5\% de las entradas o de las salidas de la pobreza fueron predichas acertadamente por el modelo. En el caso de Madagascar, los pobres transitorios han sido clasificados por el modelo, en su mayoría, como pobres permanentes (55\% para las salidas de pobreza y $41 \%$ para las entradas). En el Perú, donde la calidad de la regresión es más baja (el seudo $\mathrm{R}^{2}$ es de 0,28 , comparado con 0,35 para Madagascar), los pobres transitorios han sido clasificados por la regresión en la categoría de jamás pobres (53\% y $51 \%$ para las entradas y salidas, respectivamente) pero también una proporción importante no ha podido ser clasificada sin ambigüedad por el modelo (más o menos $40 \%$ de pobres transitorios, ver cuadros en anexo). Sin embargo, se ha rechazado, para los cuatro modelos considerados casos en el Perú, la hipótesis de que se podía combinar en una sola las diferentes transiciones de pobreza. En Madagascar, esta hipótesis no ha podido ser rechazada en la regresión incluyendo únicamente las características del jefe de hogar, y ha sido relegada al umbral de $10 \%$ y $6 \%$ en los modelos que no incluyen los shocks sufridos por los hogares (regresión $\mathrm{N}^{\circ} 2$ ), y también los shocks y las variables referentes al barrio (regresión $\mathrm{N}^{\circ} 3$ ).

\section{CONCLUSIONES}

La prioridad asignada por los países en desarrollo y por los organismos internacionales a la lucha contra la pobreza, ha conducido a refinar el diagnóstico sobre las diferentes formas de pobreza y las políticas que conviene aplicarles. En particular, la distinción entre pobreza crónica y pobreza transitoria ha inducido un cuestionamiento de las políticas pasadas, consideradas demasiado asistencialistas y a reorientarlas hacia otras que favorezcan las salidas de la pobreza y protejan a los grupos vulnerables. El modelo subyacente en esta nueva conceptualización postula que la pobreza crónica proviene de un déficit estructural de dotación de capital humano y físico mientras que la pobreza transitoria resultaría de shocks adversos que habría que prevenir y atenuar. Este enfoque implica ampliar la visión estática tradicional y extenderla hacia un análisis centrado sobre la dinámica individual de la pobreza. Ahora bien, hasta la fecha existen pocos estudios empíricos en ese dominio en los países en desarrollo, debido esencialmente a la ausencia de los datos en panel que se requieren para este tipo de análisis. Más aún, es difícil sacar conclusiones generales de esos estudios en razón de la gran heterogeneidad de las muestras, de los datos y de las opciones metodológicas que restringen y dificultan las comparaciones. Al haber adoptado metodologías rigurosamente comparables y al cubrir con nuestros dos países

(12) Se ha considerado que cuando la probabilidad predicha de que un hogar se encuentra en uno de los cuatro estados es superior al 50\%, este hogar es clasificado en el estado correspondiente. 
un amplio espectro de situaciones, cuyas coyunturas económicas y niveles de desarrollo son bastante contrastados, hemos buscado poder identificar los rasgos generales y característicos de la pobreza crónica y de la pobreza transitoria.

Luego de haber presentado el estudio y el contexto económico de cada uno de los dos países, se ha mostrado que, tanto en Perú como en Madagascar, el flujo de entradas y salidas de la pobreza son bastante superiores a lo que podría sugerir la evolución de las mediciones estáticas de la pobreza. La diversidad de la situación de los dos países permite pensar que se trata de un resultado de alcance general, que ha sido además confirmado por un conjunto de estudios del mismo tipo. La importancia de los flujos entre situaciones de pobreza y de no pobreza permite comprender por qué los programas de lucha contra la pobreza que tienen una visión estática de ella y tratan de apuntar hacia los pobres identificados como tales en un momento dado, tienen serios problemas de focalización (altas tasas de filtración y de exclusión).

Se ha mostrado igualmente las similitudes y divergencias de los perfiles de las poblaciones afectadas por los diferentes estatus de pobreza en los dos países. En primer lugar, los tests estadísticos confirman que se puede distinguir las tres poblaciones consideradas: los pobres crónicos, los pobres transitorios y los no pobres. Sin embargo, los primeros parecen distinguirse de los segundos por la intensidad de la pobreza y los factores negativos que les están asociados más que por diferencias de naturaleza. Así, un mayor tamaño del hogar y una más alta proporción de niños pequeños, así como una pobre dotación de capital humano (nivel educativo) y físico (vivienda y acceso a los servicios públicos), son otros tantos factores de riesgo asociados con la pobreza y que se ven amplificados en el caso de la pobreza crónica. La inserción en el mercado de trabajo es un factor discriminante pertinente en ambos países. Cuanto más insertados se hallan los hogares en el sector informal, mayores son los riesgos de pobreza. En los dos países, el fenómeno de la pobreza tiene un fuerte componente espacial. Los pobres tienden a residir en los barrios desfavorecidos: tanto en términos de características individuales (el ingreso promedio de los habitantes es más bajo, la tasa de informalidad es más elevada) como en términos de equipamientos públicos (acceso a la red pública de agua potable, a la electricidad, etc.). Más allá de este núcleo de características comunes, ciertos rasgos son específicos a un contexto dado. Así, los hogares jefaturados por una mujer son desfavorecidos únicamente en Madagascar y no en el Perú, siendo la primera a priori una sociedad más igualitaria. En el caso de Madagascar, de manera más clara que en el Perú, la intensidad de la inserción del hogar en el sector informal permite también distinguir las formas crónicas y transitorias de pobreza. Este resultado podría ser atribuido a la precarización brutal del empleo formal en el Perú, como resultado de diez años de liberalización del mercado de trabajo, que ha hecho más vulnerables a categorías anteriormente protegidas por los vínculos salariales (Herrera, 2001b). Por esta misma razón, probablemente, las características espaciales desempeñan un papel mayor en Madagascar que en el Perú, en tanto que la segregación residencial no es allí, a priori, más alta.

Las hipótesis que se derivan sobre la base de perfiles "incondicionales" de transiciones de pobreza han sido examinadas con ayuda de un modelo logit multinomial. Los tests de Wald han confirmado que las variables consideradas permitían distinguir entre los tres estados inicialmente considerados (de pobreza crónica, de pobreza 
transitoria y de no pobreza) pero también de diferenciar entre entradas y salidas de pobreza al interior de la categoría de los pobres transitorios. Los factores de riesgo de pobreza permanente son del todo clásicos, en gran medida comunes a ambos países y abarcan las variables tradicionales de la pobreza estática (tamaño del hogar, capital humano y físico, empleo, acceso a las infraestructuras). El nivel de riqueza del barrio de residencia juega un papel sobre la probabilidad de escapar de la pobreza, ceteris paribus. Una buena localización geográfica es por ende susceptible de crear externalidades positivas (13). Estos vínculos entre diversificación espacial de los empleos y niveles de los ingresos del barrio apuntan hacia el lazo entre desigualdad y dinámica de la pobreza. Las externalidades positivas y negativas vinculadas con la distribución (o segregación) de los empleos y las oportunidades tienen, pues, un papel que desempeñar en las dinámicas individuales de los ingresos. Ninguna de las variables de shock resultó ser significativa, en concordancia con el modelo estructural presentado más arriba. Dentro de las diferencias entre los dos países, se retiene el género del jefe del hogar. Inversamente a lo que fue observado en los perfiles incondicionales, el riesgo de pobreza crónica en Madagascar es más elevado cuando el hogar es jefaturado por una mujer. Es probable que estas últimas sufran una discriminación de ingresos mientras que la mayor vulnerabilidad de sus homólogas peruanas resultaría de un déficit en la dotación de factores.

En cuanto a las entradas y salidas de la pobreza los resultados son más decepcionantes. La capacidad predictiva de los modelos estimados resultó ser muy baja en estos casos, el papel de los shocks fue además bastante limitado (incluso considerando los shocks contemporáneos) y por último no hubo prácticamente ninguna variable común al Perú y Madagascar para dar cuenta ni de las salidas ni de las entradas en la pobreza. Sin embargo, y conformemente al modelo postulado, los factores estructurales resultaron ser menos preponderantes, mientras que los shocks demográficos y económicos tuvieron un mayor peso que en el caso de la pobreza crónica. En el Perú por ejemplo, la pérdida del jefe del hogar reduce las probabilidades de salir de la pobreza. El incremento de la mano de obra familiar y la calidad de su inserción en el mercado de trabajo (en el sector formal) favorecen las salidas de la pobreza.

A nivel de las implicaciones para la política de lucha contra la pobreza, el diagnóstico que resulta de la descomposición de la pobreza en sus componentes crónica y transitoria ha revelado que esta es un problema más agudo en el Perú que en Madagascar, donde la pobreza es no sólo más masiva sino también más crónica. Las ventajas de poner en marcha un programa de reducción de la vulnerabilidad de los hogares son, pues, más evidentes en el Perú. Nuestros resultados econométricos no permiten corroborar la idea según la cual las dotaciones de capital humano y físico son pertinentes únicamente en el caso de la pobreza crónica, mientras que los shocks explicarían las diferentes formas de pobreza transitoria. En realidad, este resultado es común a la mayor parte de estudios empíricos sobre el tema. Este resultado negativo

(13) Ver los trabajos de Jalan \& Ravallion (1997) y Ravallion \& Wodon (1997) sobre las trampas espaciales de pobreza, y en particular sobre el papel de las externalidades vinculadas con las disimilitudes en la dotación inicial de riqueza de una localidad sobre el incremento de los ingresos de los hogares. 
no se debe quizás únicamente a las dificultades muy reales de medir los shocks, sino también al hecho de no tomar en cuenta los shocks covariantes, sin embargo muy importantes en el medio urbano. Apartarse de una focalización excesiva en los determinantes micro de las transiciones de pobreza a fin de integrar la evolución del entorno macroeconómico constituye una pista de investigación que el presente estudio deja abierta.

\section{Referencias citadas}

BANCO MUNDIAL, 2000 - Attacking Poverty, 335p.; Washington: World Development Report $2000 / 1$.

BANE, M. \& ELLWOOD., 1986 - Sleeping into and out of poverty. The dynamics of spells. Journal of human Resources, winter: 1-23.

BAULCH, B. \& HODDINOTT, J. (eds.), 2000 - Economic mobility and poverty dynamics in developing countries, 184p.; London: Frank Cass Publishers.

CARTER, M., 1999 - Getting ahead or falling behind? The dynamics of poverty in post-apartheid South Africa, 45p.; Madison, USA: University of Wisconsin.

CARTER, M. \& MAY, J., 1999 - One Kind of Freedom: Poverty Dynamics in Post-Apartheid South Africa, 35p.; IFPRI/University of Natal, University of Wisconsin.

CHAUDHURI, S. \& RAVALLION, M., 1994 - How well do static indicators identify the chronically poor? Journal of Public Economics, vol. 53: 367-394.

CUMPA, M. \& WEBB, R., 1999 - Mobility and poverty dynamics in the 1990's; Brighton: Institute of Development Studies.

DATT, G. \& RAVALLION, M., 1992 - Growth and redistribution components of change in poverty measures. A decomposition with applications to Brazil and India in the 1980's. Journal of Development Economics, vol. 38, issue 2: 275-295.

DEARCON, S. \& KRISHNAN, P., 2000 - Vulnerability, seasonality and poverty in Ethiopia. In: Economic mobility and poverty dynamics in developing countries (Baulch B. \& Hoddinott J. eds.): 25-53; Portland, Oregon, USA: Frank Cass Publishers.

DOLLAR, D. \& KRAAY, A., 2000 - Growth is Good for the Poor; World Bank, march, Draft.

FIELDS, G., 2001 - Distribution and development: a new look at the developing world, 260p.; MIT Press/Russell Sage Foundation.

FREIRE, S., 2000 - Income, positional and poverty dynamics in Venezuela; Rio de Janeiro: NIP-LACEA. Conferencia, octubre del 2000.

GAIHA, R., 1988 - Income mobility in rural India. Economic Development and Cultural Change, vol. 36, $\mathbf{n}^{\circ}$ 2: 279-302.

GAIHA, R., 1989 - Are the chronically poor also the poorest in rural India? Development and Change, vol. 20: 295-322.

GAIHA, R. \& DEOLALIKAR, A., 1993 - Persistent, expected and innate poverty: estimates for semi-arid rural south India. Cambridge Journal of Economics, vol. 17, n 4: 409421.

GLEWWE, P., GRAGNOLATI, M. \& ZAMAN, H., 2000 - Who Gained from Vietnam's Boom in the 1990's? An Analysis of Poverty and Inequality Trends, 55p.; World Bank PRWP 2275.

GLEWWE, P. \& HALL, G., 1995 - Who is most vulnerable to macroeconomic shocks? Hypothesis tests using panel data from Perú; Washington, D.C.: The World Bank, LSMS Working Paper $n^{\circ} 127$. 
GROOTAERT, Ch. \& KANBUR, R., 1995 - The lucky few amidst economic decline: distributional change in Côte d'Ivoire as seen through panel data sets, 1985-88. The Journal of Development Studies, vol. 31, n² 4: 603-619.

GROOTAERT, Ch., KANBUR, R. \& OH, GI-Taik, 1997 - The Dynamics of Welfare gains and Losses: An African Case Study. Journal of Development Studies, vol. 33, n5: 635-657.

HERRERA, J., 1999 - Ajuste económico, desigualdad y movilidad. In: Pobreza y economía social. Análisis de una encuesta (ENNIV-1997) (R. Webb \& M. Ventocilla eds.): 101142; USAID, Instituto Cuanto, UNICEF.

HERRERA, J., 2001a - Poverty dynamics in Peru, 1997-1999, 56p.; Document de travail DIAL 09-2001.

HERRERA, J., 2001b - Les fonctionnaires péruviens sont-ils sur-payés ? Revue Autrepart. Numéro spécial: Les fonctionnaires au Sud (F. Roubaud \& M. Raffinot eds.), diciembre del 2001.

JALAN, J. \& RAVALLION, M., 1997 - Spacial poverty traps? Policy research working paper $N^{\circ}$ 1862; Washington: Banco Mundial.

JALAN, J. \& RAVALLION, M., 1998 - Transient poverty in postreform rural China. Journal of Comparative Economics, 26: 338-357.

JALAN, J. \& RAVALLION, M., 2000 - Is transient poverty different? Evidence for rural China. In: Economic mobility and poverty dynamics in developing countries (Baulch B. \& Hoddinott J. eds.) (2000): 82-99; Frank Cass Publishers.

JENKINS, S., 1998 - Modelling household income dynamics, Colchester, University of Essex. Draft.

JUSTINO, P. \& LITCHFIELD, J., 2002 - Poverty dynamics in rural Vietnam: winners and losers during reform, 64p.; University of Sussex: PRUS working paper $\mathrm{n}^{\circ} 11$.

LANJOUW, P. \& STERN, N., 1991 - Poverty in Palanpur. World Bank Economic Review, vol. 5, $\mathbf{n}^{\circ} 1: 23-55$.

LONG, J. \& FREESE, J., 2001 - Regression models for categorical dependent variables using Stata. Stata press.

MAHMOUDI, V., 1998 - Growth-equity decomposition of a change in poverty: an application to Iran; University of Essex. Draft.

MALUCCIO, J., HADDAD, L. \& MAY, J., 2000 - Social capital and household welfare in South Africa, 1993-98. In: Economic mobility and poverty dynamics in developing countries (Baulch B. \& Hoddinott J. eds.): 54-81; Frank Cass Publishers.

MAURIN, E. \& CHAMBAZ, C., 1996 - La persistance dans la pauvreté et son évolution. Une évolution sur données françaises. Économie et prévision, $\mathbf{N}^{\circ}$ 122: 133-152; France: INSEE.

MCCULLOCH, N. \& BAULCH, B., 1998 - Beign poor and becoming poor: poverty status and poverty transitions in rural Pakistan; IDS Working Paper $\mathrm{n}^{\circ} 79$.

MCCULLOCH, N. \& BAULCH, B., 1999 - Distinguishing the chronically from the transitorily poor: Evidence from rural Pakistan, 22p.; IDS Working Paper $n^{\circ} 97$.

MCCULLOCH, N. \& CALANDRINO, M., 2002 - Poverty Dynamics in Rural Sichuan Between 1991 and 1995, 35p.; IDS Working Papers n ${ }^{\circ} 151$.

MROZ, T. \& POPKIN, B., 1995 - Poverty and the economic transition in the Russian Federation. Economic Development and Cultural Change, vol. 44, $\mathbf{n}^{\circ}$ 1: 1-31.

OKRASA, W., 1999 - Who avoids and who escapes from poverty during the transition? Evidence from Polish panel data, 1993-96, 55p.; Wasington: Banco Mundial. Policy Research Working paper $\mathrm{N}^{\circ} 2218$.

RAKOTOMANANA, F., RAVELOSOA, R. \& ROUBAUD, F., 2001 - L'enquête 1-2-3 sur le secteur informel et la satisfaction des besoins des ménages dans l'agglomération d'Antananarivo 1995, 1998: la consolidation d'une méthode"; París: INSEE, Stateco n 94/95/96. 
RAVALliOn, M., 1996 - Comparaisons de la pauvreté. Concepts et méthodes, 334p.; Washington: Banque Mondiale: LSMS Working Paper $n^{\circ} 122$.

RAVALLION, M., 1998 - Expected Poverty under Risk. Induced Welfare Variability. Economic Journal, Vol. 98: 1171-1182.

RAVALLION, M. \& CHEN, S., 1997 - What can New Survey Data Tell Us About Recent Changes in Distribution and Poverty? World Bank Economic Review, 11(2): 357-382.

RAVALLION, M. \& WODON, Q., 1997 - Poor areas, or only poor people, 38p.; Washington: Banco Mundial. Policy Research Working Paper $N^{\circ} 1798$.

RAVELOSOA, R., 2001 - Dynamique de la pauvreté urbaine sur les quatre dernières décennies : le cas de l'agglomération d'Antananarivo. Séminaire international "La pauvreté à Madagascar : état des lieux, réflexions sur les politique de réduction et leur mise en œuvre"; Antananarivo, février.

RAZAFINDRAKOTO, M. \& ROUBAUD, F., 1999 - La dynamique du marché du travail dans l'agglomération d'Antananarivo entre 1995 et 1999 : la croissance économique profite-t-elle aux ménages ? Revue Economie de Madagascar, $\mathbf{n}^{\circ}$ 4: 103-137; Madagascar: BCM/INSTAT.

RAZAFINDRAVONONA, J., STIEFEL, D. \& PATERNOSTRO, S., 2001 - Dynamique de la pauvreté à Madagascar : 1993-1999. Séminaire international "La pauvreté à Madagascar : état des lieux, réflexions sur les politique de réduction et leur mise en œuvre"; Antananrivo, février.

REARDOM, T. \& TAYLOR, J., 199 - Agroclimatic shock, income inequality, and poverty evidence from Burkina Faso. World Development, vol. 24, $\mathbf{n}^{\circ}$ 2: 175-99.

ROEMER, M. \& GUGERTY, M.K., 1997 - Does Economic Growth Reduce Poverty?, 41p.; Havard Institue for International Development. CAER II Discussion Papers n ${ }^{\circ}$ 4-5.

ROUBAUD, F., 2001 - La mise en place d'une enquête annuelle sur l'emploi en Afrique: un exemple pour l'Afrique sub-saharienne, 216p.; París: Stateco n 94/95/96, INSEE.

SCOTT, C. \& LITCHFIELD, J., 1994 - Inequality, mobility and the determinants of income among the rural poor in Chile 1968-86; London School of Economics: STIRCED, Development Economics Research Programme DEP 53.

SCOTT, C., 2000 - Mixed fortunes: A study of poverty mobility among small farm households in Chile, 1968-86. In: Economic mobility and poverty dynamics in developing countries (Baulch B. \& Hoddinott J. eds.): 25-53; London, Inglaterra/Portland, USA: Frank Cass Publishers.

SQUIRE, L., 1993 - Fighting Poverty. American economic Review: 377-382; May.

VERDERA, F., 2000 - Cambios en el modelo de relaciones laborales en el Perú, 1970-1996, 43p.; Lima: JCAS-IEP, Occasional Paper $\mathrm{n}^{\circ} 5$.

VERGER, D., 2001 - Les approches de la pauvreté en Europe de l'Ouest : quels enseignements pour Madagascar ? Séminaire international “ La pauvreté à Madagascar : état des lieux, réflexions sur les politique de réduction et leur mise en œuvre "; Antananrivo, février.

WALKER, T. \& RYAN, J., 1990 - Village and household economies in India's semi-arid tropic; John Hopkins University Press.

YAQUB, S., 2000a - Poverty dynamics in developing countries, 42p.; University of Sussex, mimeo.

YAQUB, S., 2000b - Intertemporal welfare dynamics: extent and causes, 62p.; University of Sussex, mimeo. Background paper pour le Rapport sur le Développement Humain 2001 du PNUD. 


\section{Anexos}

Sensibilidades de las transiciones de pobreza.

Madagascar, variaciones de ingreso y transiciones de pobreza entre 1997 y 1998.

\begin{tabular}{|l|c|c|c|c|c|}
\hline vrev9798c & $\begin{array}{c}\text { Pobres } \\
\text { permanentes }\end{array}$ & $\begin{array}{c}\text { Entran en } \\
\text { pobreza }\end{array}$ & $\begin{array}{c}\text { Salen de } \\
\text { pobreza }\end{array}$ & $\begin{array}{c}\text { Jamás } \\
\text { pobres }\end{array}$ & Total \\
\hline$-50 \%$ & 13.72 & 57.95 & 0 & 8.48 & 15.43 \\
$-50 \%$ a $-30 \%$ & 12.36 & 22.60 & 0 & 9.89 & 11.78 \\
$-30 \%$ a $-10 \%$ & 15.53 & 15.42 & 0 & 16.61 & 14.21 \\
$-10 \%$ a $0 \%$ & 8.03 & 4.04 & 0 & 7.12 & 6.88 \\
0 a $+10 \%$ & 7.34 & 0 & 0 & 6.63 & 6.00 \\
$+10 \%$ a $+30 \%$ & 10.05 & 0 & 3.85 & 20.15 & 9.76 \\
$+30 \%$ a $+50 \%$ & 10.08 & 0 & 7.35 & 7.43 & 8.74 \\
más de $+50 \%$ & 22.89 & 0 & 88.80 & 23.69 & 27.20 \\
Total & 100.00 & 100.00 & 100.00 & 100.00 & 100.00 \\
\hline
\end{tabular}

Madagascar, variaciones de ingreso y transiciones de pobreza entre 1998 y 1999.

\begin{tabular}{|l|c|c|c|c|c|}
\hline vrev9798c & $\begin{array}{c}\text { Pobres } \\
\text { permanentes }\end{array}$ & $\begin{array}{c}\text { Entran en } \\
\text { pobreza }\end{array}$ & $\begin{array}{c}\text { Salen de } \\
\text { pobreza }\end{array}$ & $\begin{array}{l}\text { Jamás } \\
\text { pobres }\end{array}$ & Total \\
\hline$-50 \%$ & 13.39 & 57.89 & 0 & 8.70 & 14.40 \\
$-50 \%$ a $-30 \%$ & 14.02 & 26.94 & 0 & 19.01 & 14.15 \\
$-30 \%$ a $-10 \%$ & 14.65 & 12.67 & 0 & 19.41 & 13.70 \\
$-10 \%$ a 0\% & 7.51 & 2.50 & 0 & 7.07 & 6.38 \\
$0 \mathrm{a}+10 \%$ & 8.39 & 0 & 1.38 & 8.56 & 7.16 \\
$+10 \% \mathrm{a}+30 \%$ & 11.97 & 0 & 12.48 & 13.24 & 11.39 \\
$+30 \% \mathrm{a}+50 \%$ & 5.33 & 0 & 12.17 & 7.42 & 5.93 \\
más de $+50 \%$ & 24.74 & 0 & 73.96 & 16.59 & 26.89 \\
Total & 100.00 & 100.00 & 100.00 & 100.00 & 100.00 \\
\hline
\end{tabular}


Perú, variaciones de ingreso y transiciones de pobreza entre 1997 y 1998.

\begin{tabular}{|l|c|c|c|c|c|}
\hline vrev9798c. & $\begin{array}{c}\text { Pobres } \\
\text { permanentes }\end{array}$ & $\begin{array}{c}\text { Entran en } \\
\text { pobreza }\end{array}$ & $\begin{array}{c}\text { Salen de } \\
\text { pobreza 1 ? }\end{array}$ & $\begin{array}{c}\text { Jamás } \\
\text { pobres P P }\end{array}$ & Total \\
\hline$-50 \%$ & 14.78 & 67.77 & 0 & 6.81 & 13.39 \\
$-50 \%$ a $-30 \%$ & 10.66 & 22.48 & 0 & 12.74 & 11.90 \\
$-30 \%$ a $-10 \%$ & 16.69 & 9.62 & 0 & 19.41 & 15.83 \\
$-10 \%$ a 0\% & 13.82 & 0.13 & 0 & 11.07 & 9.39 \\
0 a $+10 \%$ & 13.28 & 0 & 1.67 & 11.11 & 9.30 \\
$+10 \%$ a $+30 \%$ & 10.66 & 0 & 8.24 & 13.91 & 11.34 \\
$+30 \%$ a $+50 \%$ & 3.68 & 0 & 12.13 & 8.09 & 6.94 \\
más de $+50 \%$ & 16.43 & 0 & 77.96 & 16.86 & 21.91 \\
Total & 100.00 & 100.00 & 100.00 & 100.00 & 100.00 \\
\hline
\end{tabular}

Perú, variaciones de ingreso y transiciones de pobreza entre 1998 y 1999.

\begin{tabular}{|l|c|c|c|c|c|}
\hline vrev9899c & $\begin{array}{c}\text { Pobres } \\
\text { permanentes }\end{array}$ & $\begin{array}{c}\text { Entran en } \\
\text { pobreza }\end{array}$ & $\begin{array}{c}\text { Salen de } \\
\text { pobreza }\end{array}$ & $\begin{array}{c}\text { Jamás } \\
\text { pobres }\end{array}$ & Total \\
\hline$-50 \%$ & 7.90 & 41.28 & 0 & 8.02 & 11.83 \\
$-50 \%$ a $-30 \%$ & 9.07 & 34.64 & 0 & 9.88 & 12.19 \\
$-30 \%$ a $-10 \%$ & 17.02 & 21.26 & 0 & 18.04 & 16.45 \\
$-10 \%$ a 0\% & 10.19 & 2.82 & 0 & 9.50 & 7.58 \\
0 a $+10 \%$ & 8.92 & 0 & 0 & 11.03 & 8.10 \\
$+10 \%$ a $+30 \%$ & 13.94 & 0 & 6.46 & 15.44 & 12.09 \\
$+30 \%$ a $+50 \%$ & 8.89 & 0 & 10.64 & 10.21 & 8.60 \\
más de $+50 \%$ & 24.07 & 0 & 82.90 & 17.89 & 23.16 \\
Total & 100.00 & 100.00 & 100.00 & 100.00 & 100.00 \\
& & & & & \\
\hline
\end{tabular}









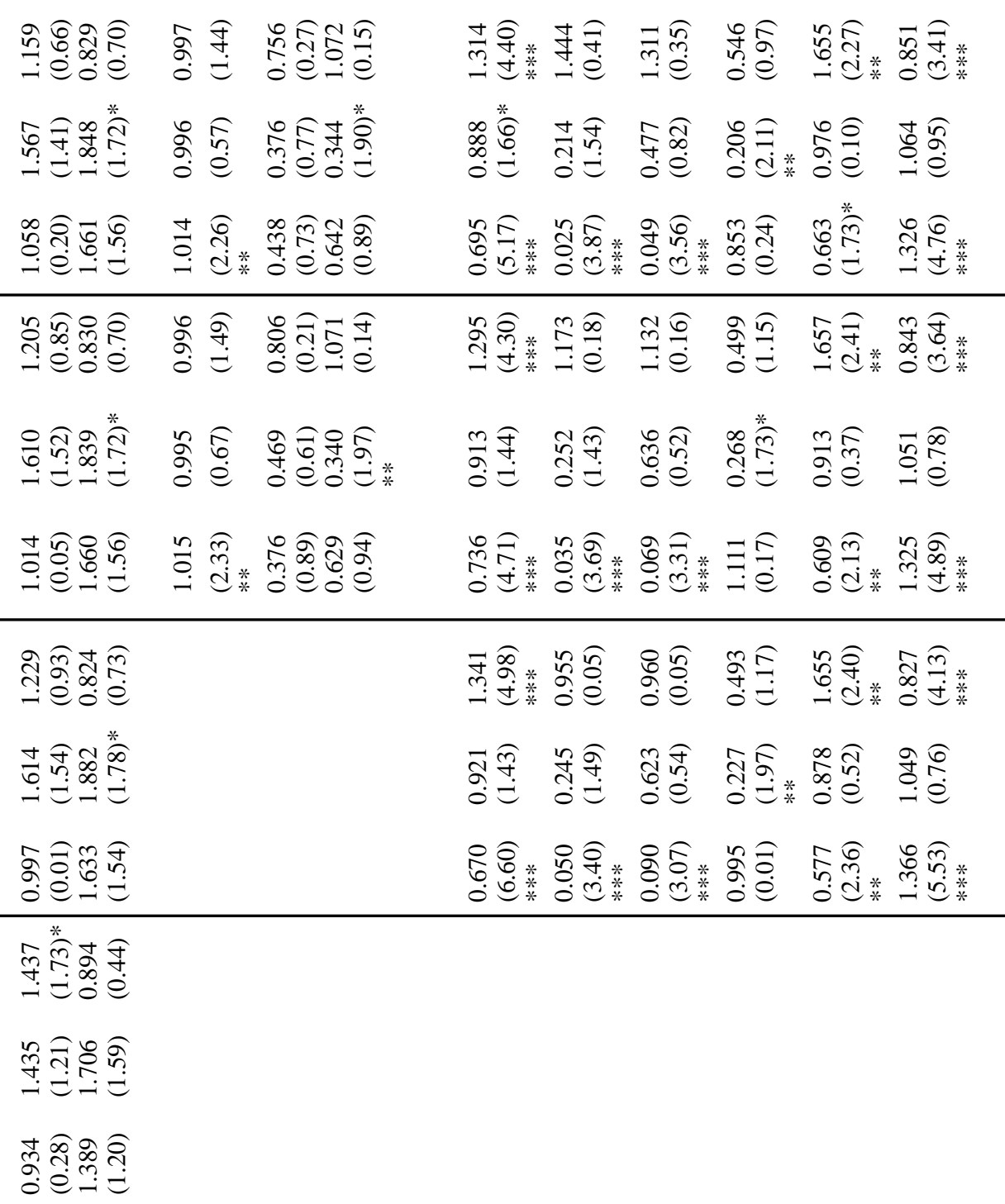

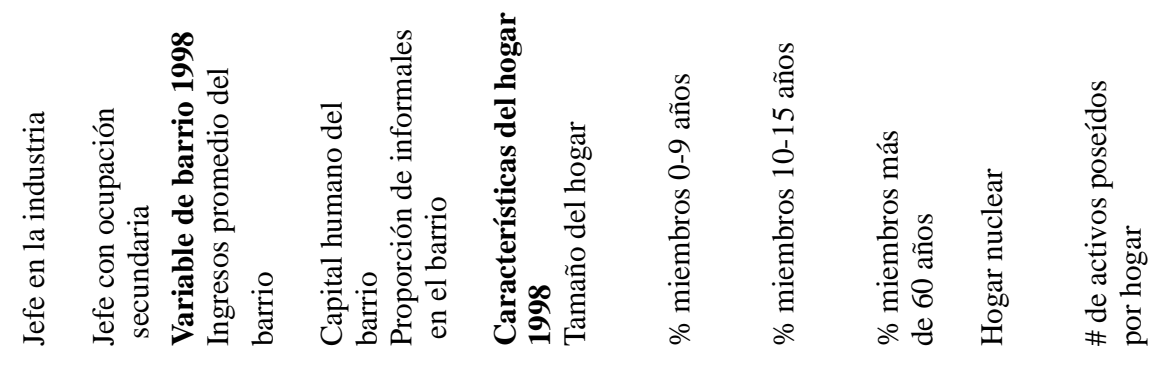




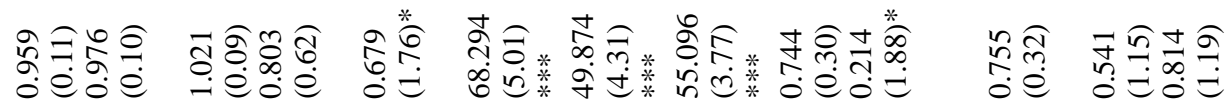

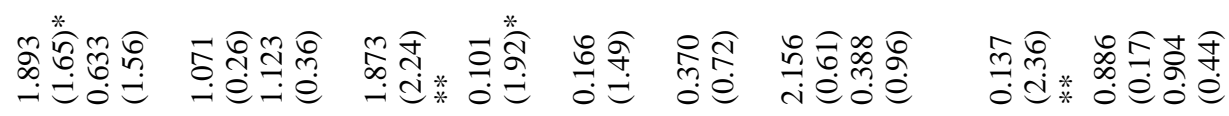

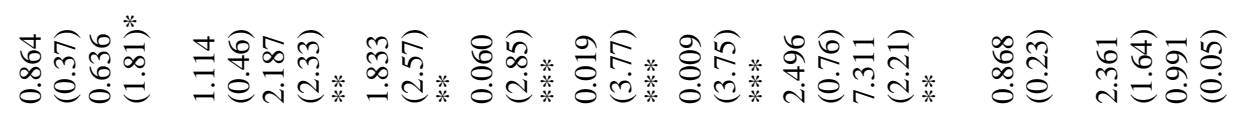

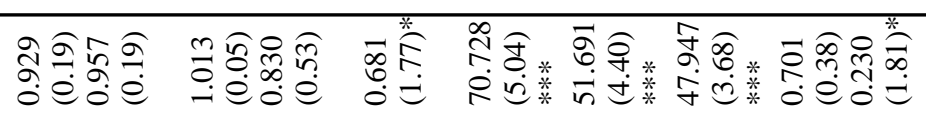

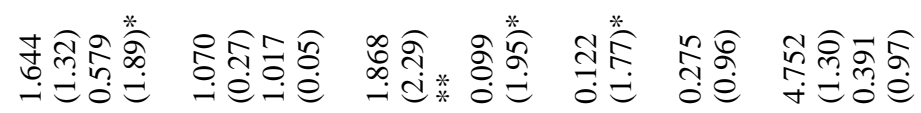

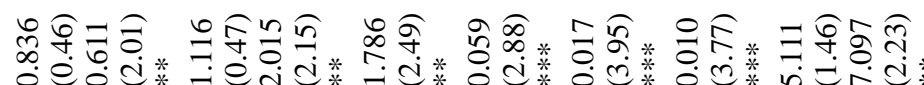

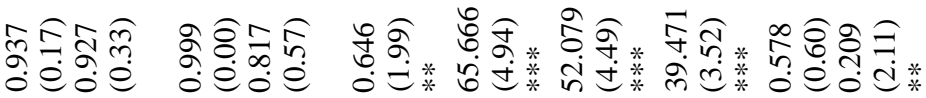

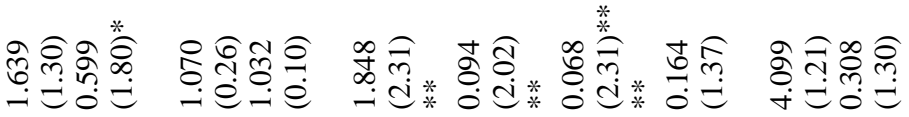

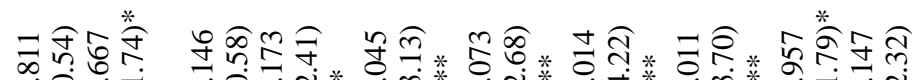

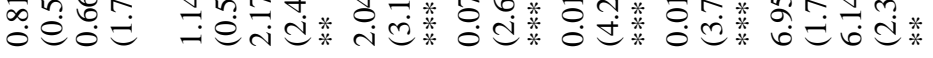

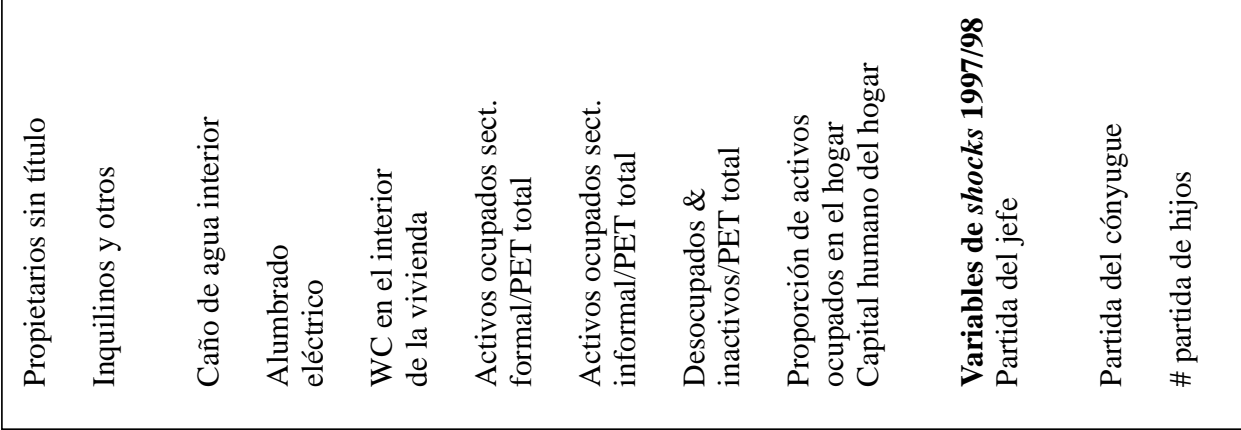




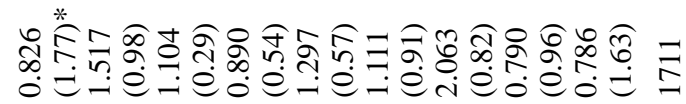

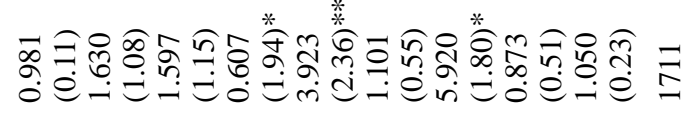



0
0

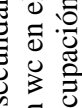

들

:

娄

क 8

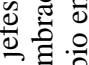

คิ

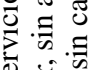

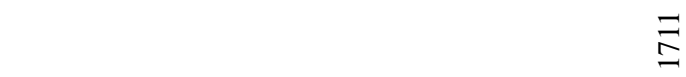

E



事

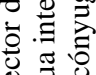

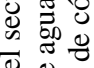

ฮ :

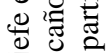

०.

I

$\frac{1}{2}$

$\frac{1}{g}$

$\stackrel{0}{\circ}$

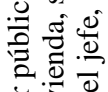

항

造 :

$\stackrel{5}{\circ}$

$\stackrel{2}{I}$

$\frac{1}{I}$

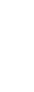

莺

节

을 늘

ฮ总

苋

. ㅎํ을

웅

产

造.

$\stackrel{0}{\circ}$

$\frac{2}{2}$

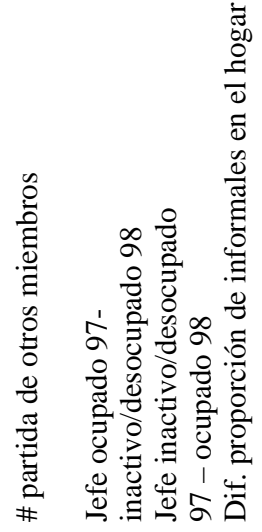

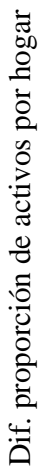

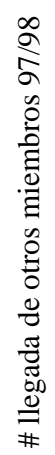

$\frac{1}{2}$

항

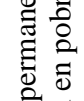

范

웜

ส

गै

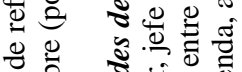

훙

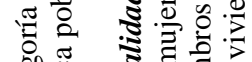

选

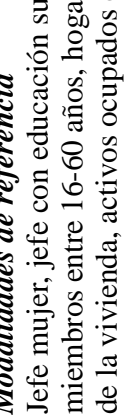




\begin{tabular}{|l|c|c|c|c|}
\hline $\begin{array}{c}\text { Multinomial } \\
\text { regresión }\end{array}$ & reg1 & reg2 & reg3 & reg4 \\
\hline Número de obs & 1711 & 1711 & 1712 & 1712 \\
Wald chi2(135) & 545 & 513 & 511 & 334 \\
Prob > chi2 & 0 & 0 & 0 & 0 \\
Pseudo R2 & 0.278 & 0.267 & 0.253 & 0.114 \\
Log likelihood & -1340 & -1359 & -1387 & -1643 \\
& & & & \\
\hline
\end{tabular}







鱼

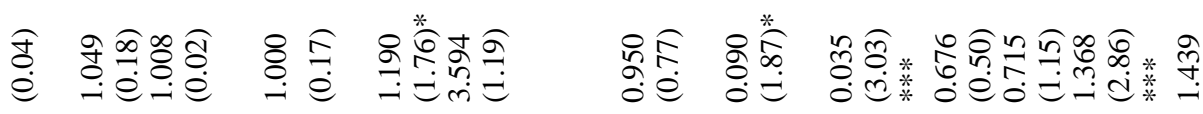
क.* d*

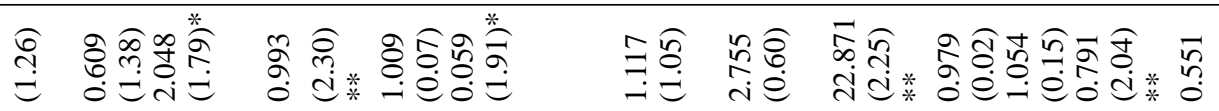
究

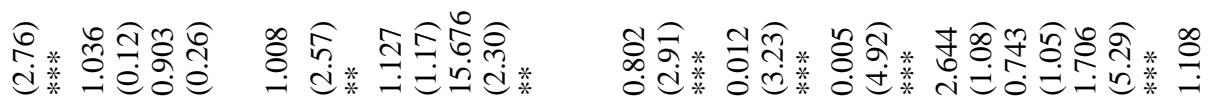

તิ๋

$\stackrel{0}{0} \doteq \overrightarrow{\mathrm{i}} \doteq$

สิ

శิ

ن.

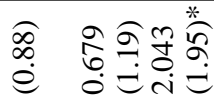



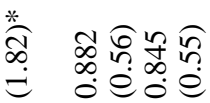



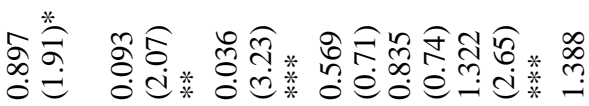

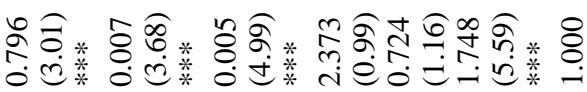

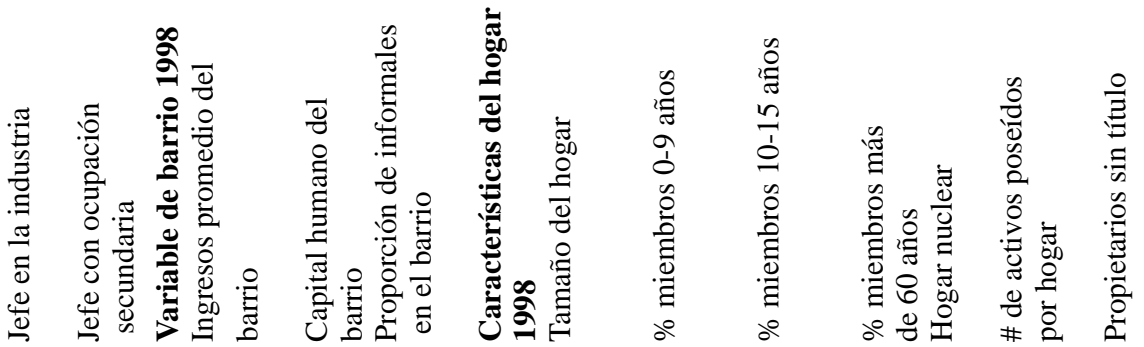




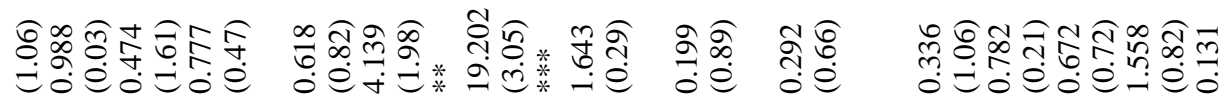





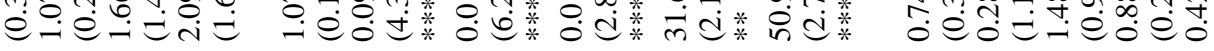



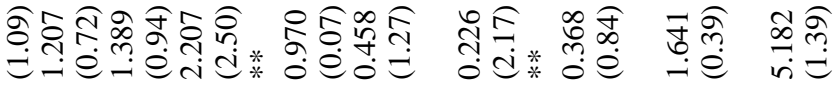

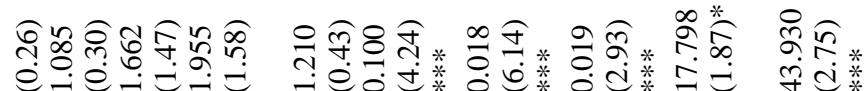

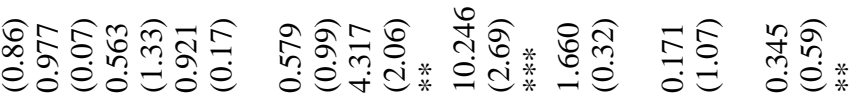



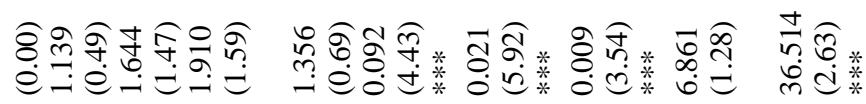

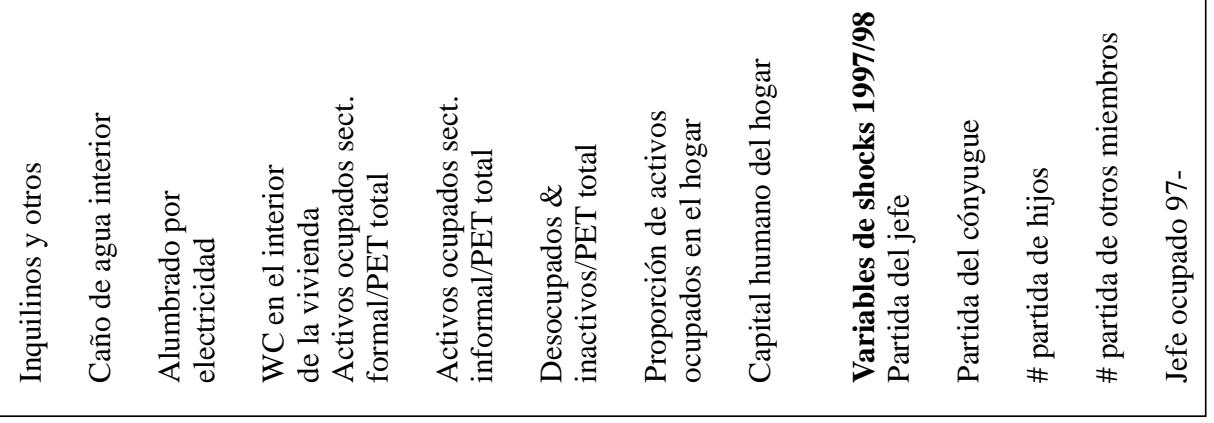




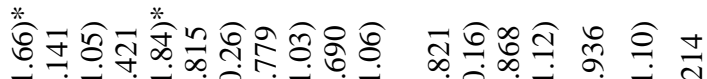

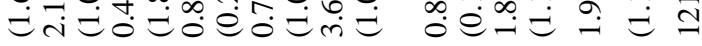

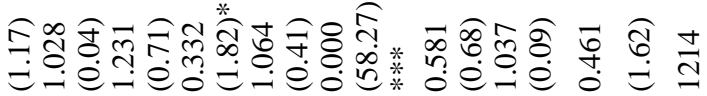

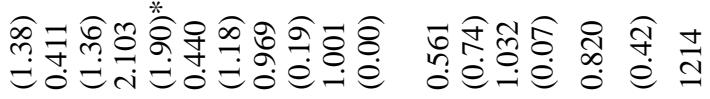

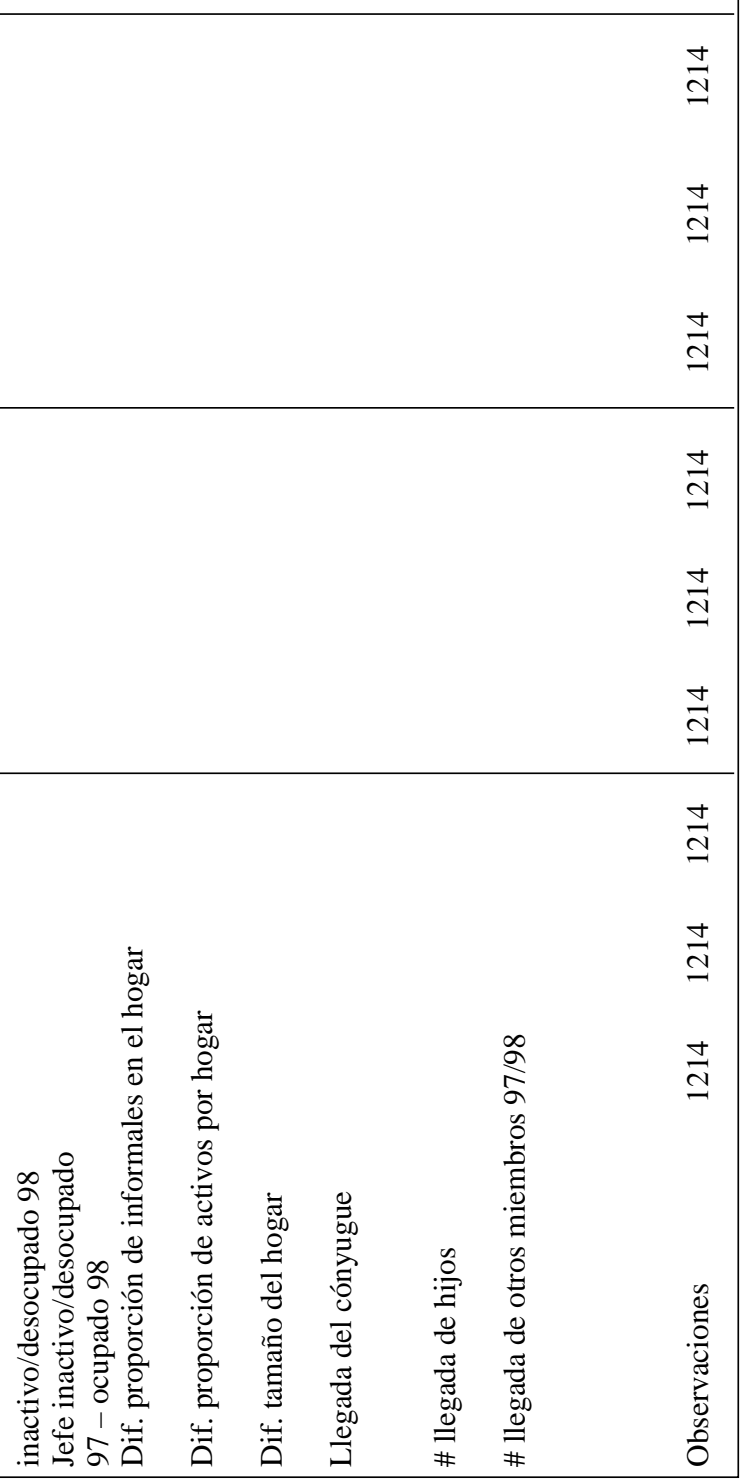



de

త્:

胥

至

프

ค

․ㅡㄹ

$\circ \frac{0}{2}$

응

\& :

으응

คิ

.$\Xi$

एक

ฐิ

$\checkmark$ :

요

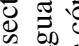

ब

๘

웅

舵

일

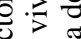

$\otimes \%$

离

$\sqrt{3}$

चू

ฮึ

言

ब声

造

.ซิ

큰

․ㅡㄹ

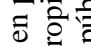

要

$\because 0$

运 文

竞

:

ษ

. ప

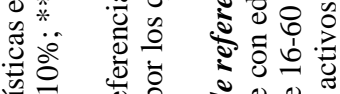




\begin{tabular}{|l|l|l|l|l|}
\hline Multinomial regresión & reg1 & reg2 & reg3 & reg4 \\
\hline Wald chi2(135) & 38120 & 425 & 421 & 245 \\
Prob > chi2 & 0 & 0 & 0 & 0 \\
Pseudo R2 & 0.353 & 0.333 & 0.327 & 0.155 \\
Log likelihood & -829 & -854 & -861 & -1081 \\
\hline
\end{tabular}

